\title{
Physical modeling of chemical membrane degradation in polymer electrolyte membrane fuel cells: Influence of pressure, relative humidity and cell voltage
}

\author{
Georg A. Futter ${ }^{a}$, Arnulf Latz ${ }^{a}$, , Thomas Jahnke ${ }^{a, *}$ \\ ${ }^{a}$ German Aerospace Center (DLR), Institute of Engineering Thermodynamics, Computational Electrochemistry, Pfaffenwaldring 38-40, 70569, Stuttgart, Germany \\ ${ }^{\mathrm{b}}$ Helmholtz Institute Ulm for Electrochemical Energy Storage (HIU), ngermanHelmholtzstra"se 11, 89081, Ulm, Germany
}

\section{A R T I C L E I N F O}

\section{Keywords:}

Polymer electrolyte membrane fuel cell

Physical modeling

Chemical membrane degradation

Membrane thinning

Reduction of OCV

\begin{abstract}
A B S T R A C T
Chemical membrane degradation causes deterioration of critical membrane properties such as gas separation which finally causes failure of polymer electrolyte membrane fuel cells (PEMFCs). In order to identify the underlying physical processes, a physics-based model of chemical membrane degradation is implemented into the novel numerical framework NEOPARD-X [1]. The existing 2D PEMFC model is extended to incorporate the mechanisms of hydrogen peroxide formation and reduction, a redox cycle of iron contaminants in the ionomer phase, radical formation due to Fenton's chemistry and radical attack on the polymer structure. Unzipping of the polymer backbone and scission of the side chains are considered as degradation mechanism. The degradation model is validated against experimental data obtained in accelerated stress tests (ASTs). From theoretical considerations, the influence of chemical membrane degradation on the cell performance is revealed. The influence of pressure, relative humidity and cell voltage on the chemical degradation is rationalized. The operating conditions strongly influence the kinetics and spacial distribution of the membrane degradation. Degradation is found to be most pronounced at elevated pressure, high relative humidity and high cell voltage close to the interface of anode catalyst layer and PEM.
\end{abstract}

\section{Introduction}

Cost reduction and improved durability are key elements to boost prevalence of the PEMFC technology. Lower platinum group metal content in the catalyst layers and cheaper bipolar plates are required to bring down the price of a cell. The main factor limiting the lifetime of PEMFCs in terms of performance is the loss of active catalyst. However, critical failure of the cell is typically due to failure of the polymer electrolyte membrane (PEM).

The membrane needs to provide low gas permeability, high proton conductivity and electrical insulation. Further, it has to resist mechanical stress due to swelling and shrinking during humidity cycling and disintegration due radical attack. Mechanical degradation can be suppressed effectively through incorporation of an e-PTFE reinforcement layer into the membrane [2,3]. However, chemical degradation of the membrane and its dependence on the operating conditions is not well understood. Therefore, this work aims to illuminate the underlying mechanisms based on physical theory.

\footnotetext{
* Corresponding author.

Email address: thomas.jahnke@dlr.de (T. Jahnke)
}

The production of hydrogen peroxide during fuel cell operation is one of the roots of chemical membrane degradation [4-7]. It may be formed as a side product of the oxygen reduction reaction (ORR) in the cathode catalyst layer (CCL) or from cross-over oxygen in the anode catalyst layer (ACL) [7]. Since its diffusion length is in the millimeter range [4], the location of chemical degradation and hydrogen peroxide production need not be the same. Due to $\mathrm{H}_{2} \mathrm{O}_{2}$ decomposition, $\mathrm{HO}^{\bullet}$ radicals are formed which are able to attack the polymer [4,8]. Further, radical formation from hydrogen peroxide is effectively catalyzed by iron contaminants [9].

Therefore, the presence of iron ions, stemming from the membrane manufacturing process [10] or metallic piping and bipolar plates [11] needs to be considered. A source from the bipolar plates can be precluded if a material which does not contain iron, e.g. graphite, is used. Another possible iron source could be non-noble metal ORR catalysts. For example, ions from $\mathrm{Fe} / \mathrm{N} / \mathrm{C}$ catalysts [12-16] could leak into the membrane [17] and accelerate the degradation. In earlier studies on chemical degradation, a constant $[5,7,18]$ or steady-state $[4,8]$ iron ion concentration is assumed. In Ref. [19] a continuous source is applied. 
The assumption of a constant $\mathrm{Fe}^{2+}$ concentration is not reasonable since it is quickly converted to $\mathrm{Fe}^{3+}$ via the Fenton's reactions. Therefore, chemical degradation would soon cease. Assuming a continuous source might only be valid in a cell with metallic bipolar plates but a high uncertainty remains concerning the magnitude of this source.

All studies mentioned above neglect the influence of the electrochemical redox reaction and transport of iron ions on the steady-state concentration which was found by Wong and Kjeang [20]. In the electrodes, $\mathrm{Fe}^{3+}$ is effectively converted back into $\mathrm{Fe}^{2+}$ via a single-electron redox reaction (Eq. (16)).

Further, iron ions are transported due to gradients of concentration and ionic potential in the CLs and PEM. Therefore, a small initial contamination with iron ions is enough to enable continuous degradation of the polymer. The model of Wong and Kjeang [20] is the only model capable to describe the dependency of chemical degradation on the cell voltage. However, this dependency was not validated.

In order to model membrane degradation in realistic fuel cell conditions, the steady-state $\mathrm{HO}^{\bullet}$ concentration needs to be determined at elevated temperatures. It is influenced by chemical reactions with $\mathrm{H}_{2}$, $\mathrm{O}_{2}, \mathrm{HOO}^{\bullet}$ and $\mathrm{H}^{\bullet}[4,8,20]$. Further, the degradation reactions with the ionomer will decrease the steady state concentration [4]. As discussed in Ref. [21], relevant reactions with $\mathrm{H}_{2}$ and $\mathrm{O}_{2}$, which are present in comparably high concentrations inside the ionomer phase, are neglected in Ref. [8]. Further, the influence of degradation reactions on the HO${ }^{\bullet}$ steady-state concentration is neglected. On the other hand, the studies $[4,20]$ neglect the influence of temperature on the reaction rates. Therefore, the sets of chemical reactions considered in these studies are valid at room temperature only.

Radical attack on the polymer structure may occur in different locations. Carboxylic acid groups on the polymer backbones have been identified as a weak spot. Here, degradation proceeds via the so called unzipping mechanism $[10,22]$ which causes continuous disintegration of the polytetrafluoroethylen (PTFE)-like polymer chains accompanied by release of $\mathrm{HF}$ and $\mathrm{CO}_{2}$. When this degradation mechanism reaches a junction of backbone and pending side chain, a side chain is cut off forming the so-called 'molecule A' which may be detected in the effluent water of the cell [23].

Scission of the side chains is a second degradation pathway [22,24]. In this case, radicals will attack the sulfonic acid group or the ether linkages on the side chain [25-30]. Subsequently, unzipping along the side chain will become operative [24] resulting in the formation of two carboxylic acid groups on the backbone. This way, side chain scission will promote degradation via the unzipping mechanism.

In this study, a model for chemical membrane degradation based on $[8,20]$ is developed and incorporated into the detailed, physical $2 \mathrm{D}$ PEMFC model of the NEOPARD-X framework [1]. To our knowledge, for the first time, a comprehensive PEMFC model takes into account the transport and electrochemical reactions of iron ions in the ionomer phase to capture the voltage dependency of degradation. An advanced set of chemical reactions which contains the relevant reactions and takes into account their temperature dependency is applied for the determination of the radical concentration under typical fuel cell operating conditions. Both, unzipping and side chain scission are considered as degradation pathways in the model. Finally, the model is validated against experimental data [31].

\section{Physical and mathematical model}

In this study, chemical membrane degradation is assumed to result from multiple coupled processes. The mechanisms included into the model are depicted schematically in Fig. 1.

The membrane exhibits a small gas permeability. Gas cross-over is described using the model of [32] where all interactions but those between the gas species and the polymer are neglected. A combination of

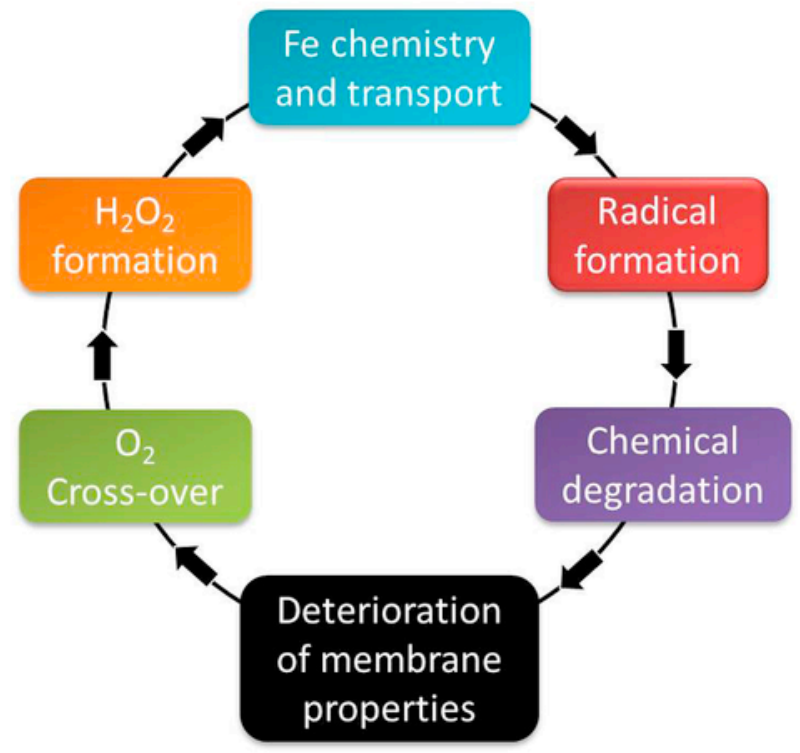

Fig. 1. Mechanisms represented in the chemical membrane degradation model.

Henry's and Fick's law allows to calculate the gas flux from permeation coefficients and gradients of the partial pressure. For a membrane in contact with a gas- or liquid phase, different permeation coefficients are applied which represent distinct transport modes. If the membrane is in contact with both phases, the two transport modes are interpolated linearly using the fraction of expanded water channels in the polymer [33]. Therefore, the conservation equation for gas species in the PEM is given by

$$
\begin{aligned}
& \frac{\partial \phi_{i o n} c^{j}}{\partial t}+\nabla \cdot\left[S_{c h}\left(-\psi_{l}^{j} \nabla p^{j}\right)\right. \\
& \left.+\left(1-S_{c h}\right)\left(-\psi_{v}^{j} \nabla p^{j}\right)\right]=0,
\end{aligned}
$$

where $\phi_{i o n}, c^{j}, S_{c h}, p^{j}$ denote the ionomer volume fraction in the PEM, the molar concentration of gas species $j$, the fraction of expanded water channels in the membrane and the gas species partial pressure respectively. The symbols $\psi_{l}^{j}$ and $\psi_{v}^{j}$ represent the permeation coefficients for the liquid- and vapor-equilibrated membrane.

For $\mathrm{O}_{2}$, the permeation coefficients are given by Ref. [32].

$$
\begin{aligned}
\psi_{v}^{\mathrm{O}_{2}}=( & 1.9 \times 10^{-11} \phi_{\mathrm{H}_{2} \mathrm{O}}+1.1 \\
& \left.\times 10^{-12}\right) \exp \left[\frac{22000}{\mathrm{R}}\left(\frac{1}{T_{\text {ref }}}-\frac{1}{T}\right)\right] \times 10^{-3}
\end{aligned}
$$

and

$\psi_{l}^{\mathrm{O}_{2}}=1.2 \times 10^{-14} \exp \left[\frac{20000}{\mathrm{R}}\left(\frac{1}{T_{\text {ref }}}-\frac{1}{T}\right)\right]$,

where $\phi_{\mathrm{H}_{2} \mathrm{O}}$ denotes the volume fraction of water in the membrane. Thus, the gas cross-over is a function of pressure, temperature and membrane hydration.

Oxygen traverses the membrane from the cathode to the anode side. Since the overpotential for the corresponding reaction is large, oxygen will react electrochemically to form hydrogen peroxide. Further, a small iron ion contamination is assumed be present in the membrane and the catalyst layers. Ions may exist in the form of ferrous- $\left(\mathrm{Fe}^{2+}\right)$ or ferric $\left(\mathrm{Fe}^{3+}\right)$ ions and are mobile in the ionomer phase of the PEM and CLs. Ferrous ions will react with hydrogen peroxide to form hydroxyl radicals and ferric ions in chemical Fenton's reactions. They are regenerated from ferric ions via an electrochemical redox reaction. The rad- 
icals may attack the polymer structure of the ionomer. The considered polymer in this work is Nafion ${ }^{\circledR} \mathrm{XL}$ with a $8.33 \mu$ m thick reinforcement layer. For the sake of simplicity, the polymer structure is described using the radically coarse-grained approach of [8]. It is discussed in detail in Section 2.5.

The governing equations for the transport of $\mathrm{H}_{2}, \mathrm{O}_{2}, \mathrm{~N}_{2}, \mathrm{H}_{2} \mathrm{O}, \mathrm{H}^{+}$ and $\mathrm{e}^{-}$in the porous electrodes and the PEM are discussed in detail in a recent publication [1]. The present study, is limited to the key species relevant for chemical membrane degradation. Further, the numerical framework NEOPARD-X, which is based on the open source software DUNE $[34,35]$ and Dumu ${ }^{X}$ [36] is presented in detail in Ref. [1].

\subsection{Performance model validation}

In order to simulate the membrane degradation within the cell under operation, coupling of the degradation model with an accurate PEMFC performance model is needed. This single cell model provides the local conditions required by the degradation model, while the degradation model provides the change of membrane properties which affect the cell performance.

Thus, in the first step the PEMFC performance model is validated against experimentally measured polarization curves [31] in Fig. 2. It should be noted that the membrane electrode assemblies (MEAs) used in this study are non-automotive. Therefore, the performance is not state-of-the-art. Since chemical membrane degradation is expected to be most severe under dry conditions and at elevated temperature, the polarization curves were measured at a temperature of $368.15 \mathrm{~K}$, a pressure of $1.5 \times 10^{5} \mathrm{~Pa}$ and $30 \%$ and $50 \%$ relative humidity. To fit the experiments, most of the model parameters used in Ref. [1] were left unchanged. Only those parameters which are expected to vary for a different active layer were changed. They are listed in Table 1. Further, in this study, the sorption isotherm of [37] was used to model the water uptake of the membrane. The experiments in Refs. [1,31] were carried out in counter- and co-flow respectively and with different MEAs. Still, excellent agreement between the model and the experiments can be observed. This demonstrates the predictive capabilities of the performance model.

At low relative humidity, the cell performance is reduced significantly due to an increase in ohmic resistance, reduced catalyst utilization and increasing oxygen transport resistance in the ionomer thin-films of the CLs [1].

\subsection{Hydrogen peroxide in a two-phase system}

For the formation and reduction of hydrogen peroxide in the CLs, the following electrochemical reaction are considered:

$\mathrm{O}_{2}+2 \mathrm{H}^{+}+2 \mathrm{e}^{-} \rightarrow \mathrm{H}_{2} \mathrm{O}_{2}$

$\mathrm{H}_{2} \mathrm{O}_{2}+2 \mathrm{H}^{+}+2 \mathrm{e}^{-} \rightarrow 2 \mathrm{H}_{2} \mathrm{O}$

The corresponding equilibrium voltages are $0.695 \mathrm{~V}$ and $1.76 \mathrm{~V}$ respectively. From the equilibrium voltage the reaction overpotential is calculated as

$\eta=\Phi_{\text {elec }}-\Phi_{\text {ion }}-E^{0}$

where $\Phi_{\text {elec }}, \Phi_{\text {ion }}$ and $E^{0}$ denote the electrode potential, the ionic potential and the equilibrium voltage respectively. The reaction rates are modeled using Tafel and symmetric Butler-Volmer kinetics respectively [20]. They are given by

$$
r^{\mathrm{H}_{2} \mathrm{O}_{2}, \mathrm{f}}=A_{e f f} i^{0} \frac{c^{\mathrm{O}_{2}}}{c_{r e f}^{\mathrm{O}_{2}}} \chi \exp \left(\frac{-\mathrm{F} \eta}{\mathrm{R} T}\right)
$$

a)
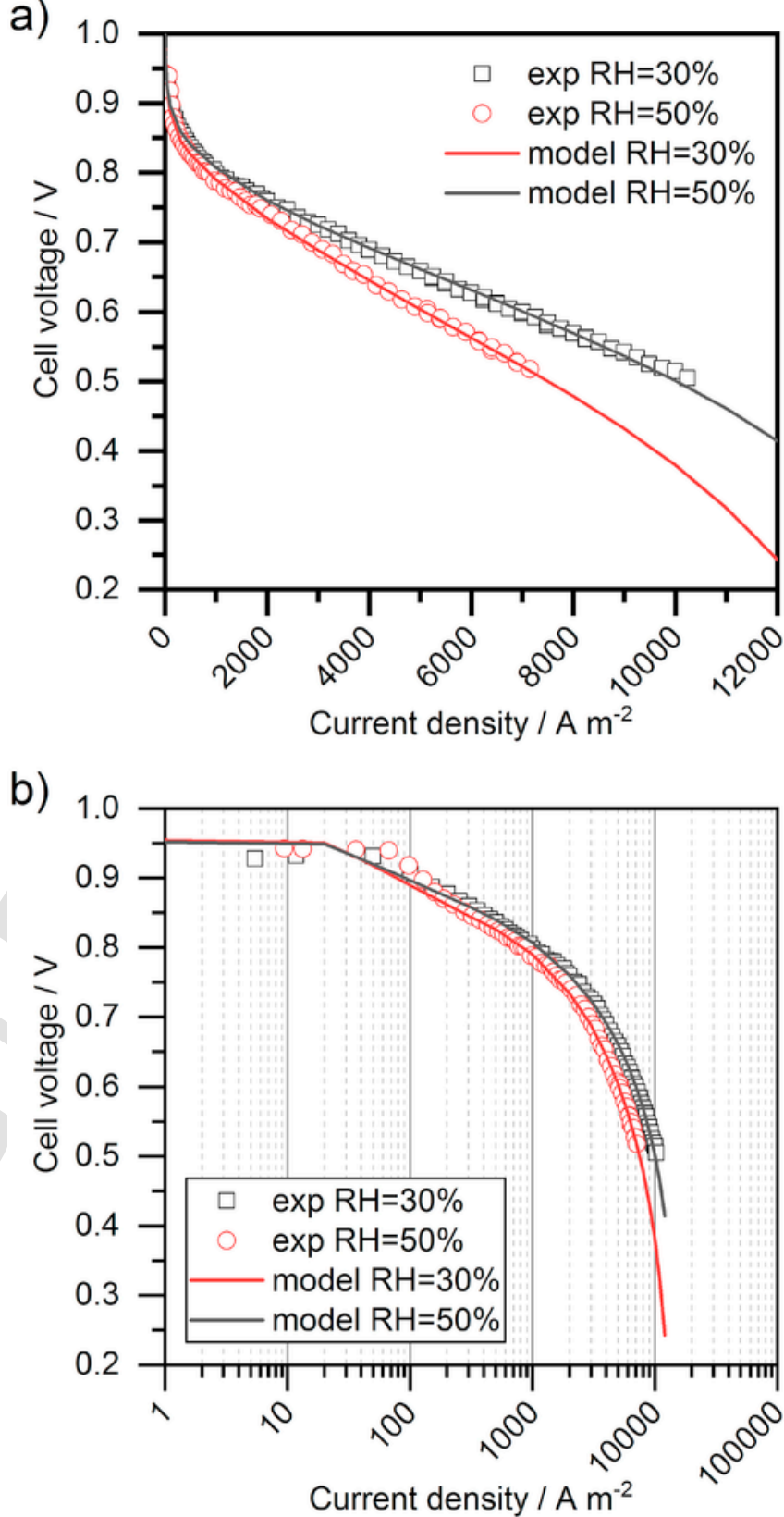

Fig. 2. Comparison of simulated and experimental polarization curves: a) linear current density scale. b) logarithmic current density scale.

and

$r^{\mathrm{H}_{2} \mathrm{O}_{2}, \mathrm{r}}=2 A_{e f f} i^{i} \frac{c^{\mathrm{H}_{2} \mathrm{O}_{2}}}{c_{r e f}^{\mathrm{H}_{2} \mathrm{O}_{2}}} \sinh \left(\frac{\alpha^{\mathrm{H}_{2} \mathrm{O}_{2}, \mathrm{r}} \mathrm{F} \eta}{\mathrm{R} T}\right)$,

where the symbols $A_{e f f}, i^{0}$ and $\chi$ denote the effective active surface area, the exchange current density and the $\mathrm{H}_{2} \mathrm{O}_{2}$ selectivity. The parameters used in this study are presented in Table 2 .

In the porous electrodes, hydrogen peroxide is transported via convection and diffusion in the gas- and liquid phase. In a general form the balance equation of a species $j$ is expressed as [1].

$\frac{\partial \xi^{j}}{\partial t}+\nabla \cdot \Psi^{j}-q^{j}=0$ 
Table 1

Model parameters for validation.

\begin{tabular}{|c|c|c|}
\hline Symbol/Value & Units & Comment \\
\hline \multicolumn{3}{|l|}{ Lambda control: } \\
\hline$i_{\min }=600 / 1000^{*}$ & $\mathrm{~A} \mathrm{~m}^{-2}$ & - \\
\hline$\lambda^{\text {flux }, \mathrm{O}_{2}}=2 / 10^{*}$ & - & - \\
\hline$\lambda^{f l u x, \mathrm{H}_{2}}=1.2 / 10^{*}$ & - & - \\
\hline \multicolumn{3}{|l|}{ ORR: } \\
\hline \multicolumn{3}{|l|}{ ECSA: } \\
\hline$A_{\text {anode }}=1.26 \times 10^{7}$ & $\mathrm{~m}^{2} \mathrm{~m}^{-3}$ & measurement $\mathrm{t}^{\mathrm{a}}$ \\
\hline$A_{\text {cathode }}=1.17 \times 10^{7}$ & $\mathrm{~m}^{2} \mathrm{~m}^{-3}$ & calculated \\
\hline \multicolumn{3}{|l|}{ Ionomer film model: } \\
\hline$\delta_{\text {ion }}=7 \times 10^{-9}$ & $\mathrm{~m}$ & fitted \\
\hline$A=100$ & $\mathrm{~s} \mathrm{~m}^{-1}$ & fitted \\
\hline$B=3 \times 10^{4}$ & $\mathrm{~s} \mathrm{~m}^{-1}$ & fitted \\
\hline$C=-5.5$ & - & fitted \\
\hline $\begin{array}{l}\text { PTFE reinforcement in th } \\
\phi_{\text {ion }}=1 / 0.4^{\mathrm{b}}\end{array}$ & - & estimated \\
\hline
\end{tabular}

*value for the polarization curve- and AST simulations respectively.

a Corresponds to a Pt loading of $0.6 \mathrm{mg} \mathrm{cm}^{-2}$.

b Values out- and inside the reinforcement layer respectively.

Table 2

Model parameters for $\mathrm{H}_{2} \mathrm{O}_{2}$-formation and -reduction.

\begin{tabular}{lll}
\hline Symbol & Value/Units & Reference \\
\hline$A_{e f f}$ & $A\left(1-\theta^{\mathrm{PtOx}}\right) / \mathrm{m}^{2} \mathrm{~m}^{-3}$ & a \\
$i^{0, \mathrm{H}_{2} \mathrm{O}_{2}, \mathrm{f}}$ & $4 \times 10^{-10} / \mathrm{A} \mathrm{m}^{-2}$ & fitted \\
$i^{0, \mathrm{H}_{2} \mathrm{O}_{2}, \mathrm{r}}$ & $1 \times 10^{-5} / \mathrm{A} \mathrm{m}^{-2}$ & {$[20]$} \\
$\chi$ & {$\left[\frac{1980+32.4 \lambda}{1167.4 \mathrm{EW}(1+0.0648 \lambda)}\right]^{2}$} & {$[38]$} \\
$\alpha^{\mathrm{H}_{2} \mathrm{O}_{2}, \mathrm{r}}$ & 0.32 & {$[18]$} \\
$c_{r e f}^{\mathrm{O}_{2}}$ & $40.88 / \mathrm{mol} \mathrm{m}^{-3}$ & {$[20]$} \\
$c_{r e f}^{\mathrm{H}_{2} \mathrm{O}_{2}}$ & $40.88 / \mathrm{mol} \mathrm{m}^{-3}$ & {$[20]$} \\
\hline
\end{tabular}

a The active area $A$ is given in Table 1 . The surface coverage of platinum oxides $\theta^{\mathrm{PtOx}}$ is calculated according to [1].

The first and second term of Eq. (9) for $\mathrm{H}_{2} \mathrm{O}_{2}$ are given by

$\xi^{\mathrm{H}_{2} \mathrm{O}_{2}}=\phi \sum_{\alpha=1}^{\mathrm{M}} \rho_{m o l, \alpha} x_{\alpha}^{\mathrm{H}_{2} \mathrm{O}_{2}} S_{\alpha}$

and

$\Psi^{\mathrm{H}_{2} \mathrm{O}_{2}}=-\sum_{\alpha=1}^{\mathrm{M}}\left(\rho_{m o l, \alpha} x_{\alpha}^{\mathrm{H}_{2} \mathrm{O}_{2}} \mathbf{v}_{\alpha}+\mathbf{d}_{\alpha}^{\mathrm{H}_{2} \mathrm{O}_{2}}\right)$,

respectively, where $\phi, \rho_{\text {mol, } \alpha}, x_{\alpha}^{\mathrm{H}_{2} \mathrm{O}_{2}}, S_{\alpha}$ denote the porosity, the molar density, the mole fraction of $\mathrm{H}_{2} \mathrm{O}_{2}$ in phase $\alpha$ and the saturation of phase $\alpha$ respectively. The symbol $\mathrm{M}$ denotes the number of fluid phases and is equal to two. For the phase velocity $\mathbf{v}_{\alpha}$, a multi-phase Darcy approach is applied:

$\mathbf{v}_{\alpha}=-\frac{k_{r \alpha}}{\mu_{\alpha}} \mathbf{K} \nabla p_{\alpha}$.

Here, $\mathbf{K}$ represent the intrinsic permeability of the porous medium. The permeability values for the different layers of the electrode are taken from Ref. [1] and are given in Table 3. The symbols $k_{r \alpha}, \mu_{\alpha}$ and $p_{\alpha}$ de-

Table 3

The permeability values used in this study for different layers of the electrodes.

\begin{tabular}{ll}
\hline Layer & Permeability $/ \mathrm{m}^{2}$ \\
\hline GDL & $1.8 \times 10^{-11}$ \\
MPL & $3.33 \times 10^{-15}$ \\
CL & $2 \times 10^{-15}$ \\
\hline
\end{tabular}

note the relative permeability, the dynamic viscosity and the pressure of phase $\alpha$ respectively. The diffusive flux density of hydrogen peroxide $\mathbf{d}_{\alpha}^{\mathrm{H}_{2} \mathrm{O}_{2}}$ takes into account Fickian- and Knudsen diffusion [1].

In the considered two-phase system, hydrogen peroxide has a high affinity for the liquid water phase. This manifests itself in a high value of the Henry coefficient $\left(6.81 \times 10^{2}\right.$ to $1.382 \times 10^{3} \mathrm{~mol} \mathrm{~m}^{-3} \mathrm{~Pa}^{-1}$ [39]) which exceeds the value for e.g. oxygen by seven to eight orders of magnitude. The mole fraction of $\mathrm{H}_{2} \mathrm{O}_{2}$ in the liquid- and ionomer phase is calculated using

$x_{l}^{\mathrm{H}_{2} \mathrm{O}_{2}}=x_{\text {ion }}^{\mathrm{H}_{2} \mathrm{O}_{2}}=\frac{x_{g}^{\mathrm{H}_{2} \mathrm{O}_{2}} p_{g}}{p_{\text {sat }}^{\mathrm{H}_{2} \mathrm{O}_{2}} a_{l}^{\mathrm{H}_{2} \mathrm{O}_{2}}}$,

where the vapor pressure, $p_{\text {sat }}^{\mathrm{H}_{2} \mathrm{O}_{2}}$, and the activity of $\mathrm{H}_{2} \mathrm{O}_{2}$ in the liquid phase, $a_{l}^{\mathrm{H}_{2} \mathrm{O}_{2}}$, are calculated using the relations given in Ref. [40]. Since, in equilibrium, the resulting concentration of hydrogen peroxide in the liquid phase is extremely high compared to the gas phase concentration, a low value for the exchange current density of the $\mathrm{H}_{2} \mathrm{O}_{2}$-formation reaction was chosen in this study (see Table 2) to obtain concentrations similar to those reported in the single-phase model of [20]. The value used here is five to eleven orders of magnitude below other values given in literature $[18,20,41]$. The rigorous treatment of hydrogen peroxide in the two-phase system is a fundamental novelty in the modeling of chemical membrane degradation.

In the PEM, for secondary species like hydrogen peroxide, iron ions and radicals, the transport is assumed to be purely diffusive. Therefore, the corresponding balance equation for an arbitrary species $j$ in the membrane is given by

$\frac{\partial \phi_{i o n} c^{j}}{\partial t}+\nabla \cdot\left(-D_{e f f}^{j} \nabla c^{j}\right)-q^{j}=0$,

where $\phi_{\text {ion }}$ denotes the volume fraction of the ionomer phase (see Table $1)$. For hydrogen peroxide, a diffusion coefficient $D^{\mathrm{H}_{2} \mathrm{O}_{2}}=6.8 \times 10^{-11}$ $\mathrm{m}^{2} \mathrm{~s}^{-1}$ [42] is used. For the calculation of arbitrary effective transport parameters $P$ in the ionomer phase (e.g. diffusion coefficients, mobilities, conductivities, ...), a Bruggemann correction is employed:

$P_{\text {eff }}=\phi_{i o n}^{1.5} P$.

This correction is applied to all transport properties inside the reinforcement layer of the PEM and in the catalyst layers. This standard approach is used due to a lack of data on the actual micro-structure of the ionomer phase in the PEM reinforcement and the CLs. Tomographic measurements of the ionomer distribution in these layers are required to obtain improved relations for effective transport properties.

The sink term $q^{\mathrm{H}_{2} \mathrm{O}_{2}}$ inside the PEM is calculated based on the system of reactions presented in Section 2.4 using Eq. (23).

\subsection{Iron ions}

Chemical membrane degradation strongly depends on the operating conditions. The strongest impact has the cell voltage. Further, degradation is found to be most severe on the anode side of the membrane [31]. Since the anode potential does not change much under load, the hypothesis of an electrochemical process leading to radical formation and subsequent chemical degradation can be ruled out. Therefore, a different process which depends on cell voltage is required in order to explain the experimental observations. In Ref. [20] the presence of an iron ion redox cycle in combination with iron transport in the PEM and CLs is assumed. Iron ions react via

$\mathrm{Fe}^{3+}+\mathrm{e}^{-} \rightleftharpoons \mathrm{Fe}^{2+}$

in the electrodes and move due to concentration- and ionic potential gradients in the ionomer phase. 
This theory is useful for two reasons: (i) $\mathrm{Fe}^{2+}$ is regenerated from $\mathrm{Fe}^{3+}$ via Eq. (16) so that degradation does not cease with only a little amount of iron present and (ii) the transport of iron ions depends on the cell voltage, which could be the missing mechanism to explain the voltage dependency of chemical membrane degradation. For these reasons, the model of [20] for the iron ions is adapted in this study.

The rate of the electrochemical iron ion redox reaction in the electrodes is calculated as [20].

$$
\begin{aligned}
r^{\mathrm{Fe}}= & A_{\text {eff }} k^{\mathrm{Fe}} \mathrm{F} \sqrt{c^{\mathrm{Fe} 2+} c^{\mathrm{Fe} 3+}} \\
& \times\left[\exp \left(\frac{\alpha^{\mathrm{Fe}} \mathrm{F} \eta^{\mathrm{Fe}}}{\mathrm{R} T}\right)-\exp \left(\frac{-\alpha^{\mathrm{Fe}} \mathrm{F} \eta^{\mathrm{Fe}}}{\mathrm{R} T}\right)\right],
\end{aligned}
$$

with $k^{\mathrm{Fe}}=1 \times 10^{7} \mathrm{~m} \mathrm{~s}^{-1}, \alpha^{\mathrm{Fe}}=0.5$ and the temperature-dependent equilibrium voltage [43].

$$
\begin{aligned}
E^{0, \mathrm{Fe}}= & -1.23 \times 10^{-2}+4.147 \times 10^{-3} T \\
& -5.111 \times 10^{-6} T^{2}+\frac{\mathrm{R} T}{\mathrm{~F}} \ln \left(\frac{c^{\mathrm{Fe} 3+}}{c^{\mathrm{Fe} 2+}}\right) .
\end{aligned}
$$

The flux density of a trace ion $j$ in the ionomer phase of the CLs and the PEM is described with a Nernst-Plank-type equation [20].

$$
\Psi^{j}=-D^{j} \nabla c^{j}-u^{j} z^{j} c^{j} \mathrm{~F} \nabla \Phi_{i o n},
$$

where $D^{j}, c^{j}, u^{j}$, and $z^{j}$ denote the diffusion coefficient, the concentration, the mobility and the charge number of ion $j$ respectively. The diffusion coefficient is expressed as a function of mobility using the Nernst-Einstein-relation

$D^{j}=u^{j} \mathrm{R} T$.

For ferrous and ferric ions, mobilities of $1.25 \times 10^{-13}$ and $1.25 \times 10^{-14} \mathrm{~s} \mathrm{~mol} \mathrm{~kg}{ }^{-1}$ were used respectively [20]. Again, effective ion mobilities are calculated using Eq. (15).

\subsection{Radical formation}

The considered set of chemical reactions involved in the radical formation together with the corresponding kinetic parameters is given in Table 4.

\begin{tabular}{|c|c|c|c|c|}
\hline Nr. & Reaction & $\begin{array}{l}k_{r e f}^{i} / \mathrm{m}^{3} \\
\mathrm{~mol}^{-1} \mathrm{~s}^{-1}\end{array}$ & $\begin{array}{l}E_{\text {act }}^{i} / \mathrm{J} \\
\mathrm{mol}^{-1}\end{array}$ & Ref. \\
\hline 1 & $\begin{array}{l}\mathrm{Fe}^{2+}+\mathrm{H}_{2} \mathrm{O}_{2}+\mathrm{H}^{+} \rightarrow \mathrm{Fe}^{3+}+ \\
\mathrm{HO}^{\bullet}+\mathrm{H}_{2} \mathrm{O}\end{array}$ & $6.5 \times 10^{-2}$ & $3.54 \times 10^{4}$ & [44] \\
\hline 2 & $\begin{array}{l}\mathrm{Fe}^{3+}+\mathrm{H}_{2} \mathrm{O}_{2}+\mathrm{H}^{+} \rightarrow \mathrm{Fe}^{2+}+ \\
\mathrm{HOO}+\mathrm{H}^{+}\end{array}$ & $4 \times 10^{-8}$ & $1.26 \times 10^{5}$ & [4] \\
\hline 3 & $\begin{array}{l}\mathrm{Fe}^{2+}+\mathrm{HOO}^{\bullet}+\mathrm{H}^{+} \rightarrow \mathrm{Fe}^{3+}+ \\
\mathrm{H}_{2} \mathrm{O}_{2}\end{array}$ & $1.2 \times 10^{3}$ & $4.2 \times 10^{4}$ & {$[45,46]$} \\
\hline 4 & $\underset{+}{\mathrm{Fe}^{3+}+\mathrm{HOO}^{\bullet} \rightarrow \mathrm{Fe}^{2+}+\mathrm{O}_{2}+\mathrm{H}}$ & $2 \times 10^{1}$ & $3.3 \times 10^{4}$ & {$[46,47]$} \\
\hline 5 & $\begin{array}{l}\mathrm{Fe}^{2+}+\mathrm{HO}^{\bullet}+\mathrm{H}^{+} \rightarrow \mathrm{Fe}^{3+}+ \\
\mathrm{H}_{2} \mathrm{O}\end{array}$ & $2.5 \times 10^{5}$ & $9 \times 10^{3}$ & {$[45,48]$} \\
\hline 6 & $\mathrm{HO}^{\bullet}+\mathrm{H}_{2} \mathrm{O}_{2} \rightarrow \mathrm{HOO}^{\bullet}+\mathrm{H}_{2} \mathrm{O}$ & $2.7 \times 10^{4}$ & $1.4 \times 10^{4}$ & {$[49,50]$} \\
\hline 7 & $\begin{array}{l}\mathrm{HOO}^{\bullet}+\mathrm{H}_{2} \mathrm{O}_{2} \rightarrow \mathrm{HO}^{\bullet}+\mathrm{H}_{2} \mathrm{O}+ \\
\mathrm{O}_{2}\end{array}$ & $3 \times 10^{-3}$ & $3 \times 10^{4}$ & {$[51,52]$} \\
\hline 8 & $2 \mathrm{HOO}^{\bullet} \rightarrow \mathrm{H}_{2} \mathrm{O}_{2}+\mathrm{O}_{2}$ & $\begin{array}{l}8.6 \times 10^{2} \\
/ s^{-1}\end{array}$ & $2.06 \times 10^{4}$ & {$[53,54]$} \\
\hline 9 & $\mathrm{HO}^{\bullet}+\mathrm{H}_{2} \rightarrow \mathrm{H}^{\bullet}+\mathrm{H}_{2} \mathrm{O}$ & $4.2 \times 10^{7}$ & $0^{\mathrm{a}}$ & [49] \\
\hline 10 & $\mathrm{H}^{\bullet}+\mathrm{O}_{2} \rightarrow \mathrm{HOO}^{\bullet}$ & $2.1 \times 10^{10}$ & $0^{\mathrm{a}}$ & [49] \\
\hline
\end{tabular}

The rate constant of the irreversible reactions $i$ for a given temperature is calculated with an Arrhenius approach

Table 4

Set of chemical reactions considered in the model.

a No activation energy available. $k^{i}=k_{r e f}^{i} \exp \left[\frac{E_{a c t}^{i}}{\mathrm{R}}\left(\frac{1}{T_{r e f}}-\frac{1}{T}\right)\right]$,

where the reference temperature $T_{r e f}=298.15 \mathrm{~K}$. The corresponding reaction rates are given by

$r^{i}=\phi_{i o n} k^{i} \prod_{j}\left(c^{j}\right)^{\nu^{i, j}}$

where $j$ denotes the educt species of reaction $i$ with the corresponding stoichiometry coefficient $\nu^{i, j}$.

The set of reactions is similar to the one used in Ref. [8]. However, reactions 9 and 10 were added since they are relevant in operating PEMFCs [4]. To the authors knowledge, for these reactions, no activation energy is available in the scientific literature. Especially reaction 9 may lower the hydroxyl radical concentration significantly, depending on its activation energy. Therefore, the hydroxyl radical concentrations calculated with the model represent the upper limit.

A sensitivity study for the activation energies of reactions 9 and 10 was performed to investigate the importance of the reactions. For this purpose, $100 \mathrm{~h}$ of chemical membrane degradation at OCV, a pressure of $1.5 \times 10^{5} \mathrm{~Pa}$, a relative humidity of $30 \%$ and a temperature of $368.15 \mathrm{~K}$ were simulated. The activation energies of reactions 9 and 10 were varied in a broad range from 0 to $9 \times 10^{4} \mathrm{~J} \mathrm{~mol}^{-1}$ and the results are depicted in Fig. 3.

An exponential decrease of the FER with increasing values of $E_{a c t}^{9}$ can be observed as hydroxyl radicals are decomposed efficiently via reaction 9. In the present model, the kinetics of reaction 10 is insignificant. However, reaction 10 will become relevant if degradation mechanisms involving hydrogen radicals [29] are considered.

It should be noted that the temperature-dependence of all reaction kinetics was neglected in Ref. [20], so the results are applicable to ex-situ experiments only. Further, in Ref. [8], an analytical solution for the steady-state $\mathrm{HO}^{\bullet}$ concentration was derived, neglecting the influence of the degradation reactions. This is a simplification which may lead to an drastic overestimation of the $\mathrm{HO}^{\bullet}$ concentration up to two orders of magnitude [4]. Both simplifications mentioned above are avoided in the present study.

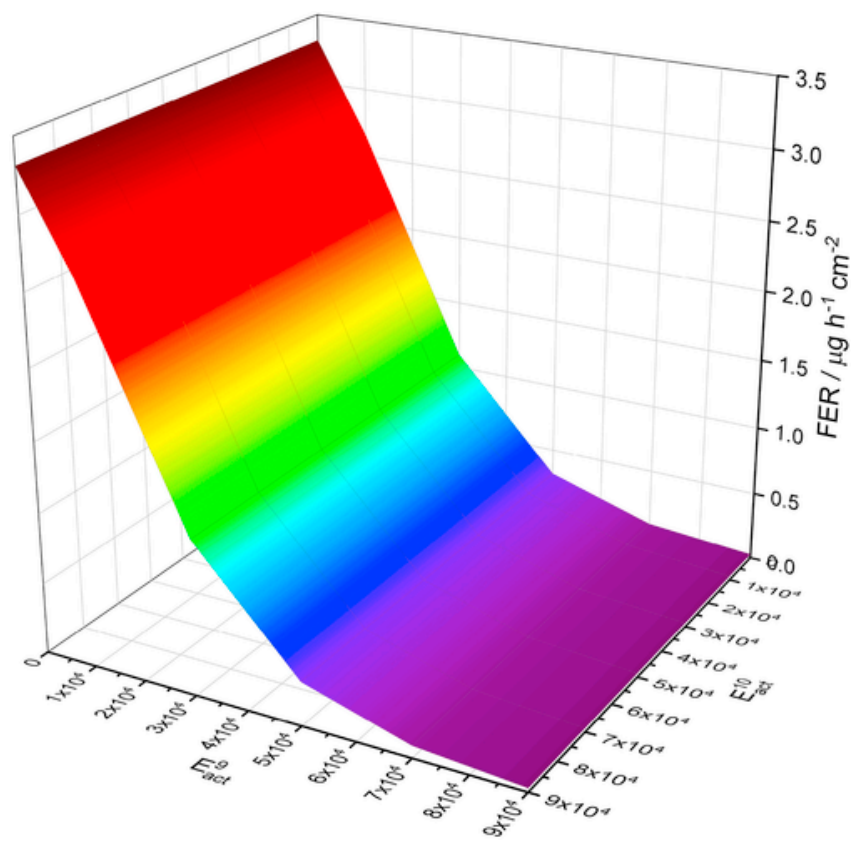

Fig. 3. Model sensitivity to the activation energies of reactions 9 and 10 . 
For each radical species involved in the reactions, a balance equation equal to Eq. (14) is solved inside the PEM. The diffusion coefficients used in this study for $\mathrm{H}^{\bullet}, \mathrm{HO}^{\bullet}$ and $\mathrm{HOO}^{\bullet}$ are $9 \times 10^{-10}, 6.8 \times 10^{-11}$ and $3 \times 10^{-9} \mathrm{~m}^{2} \mathrm{~s}^{-1}$ respectively [4]. The source terms for species $j$ due to the reactions $i$ are given by

$q^{j}=\sum_{i} \sum_{j} v^{i, j} r^{i}$

\subsection{Polymer structure and radical attack}

The polymer structure of Nafion ${ }^{\circledR}$ is depicted in Fig. 4 a). It consists of a PTFE-like backbone with pending side-chains, terminating in a sulfonic acid group. For the attack of radicals on the polymer structure, different locations have been identified. In this study, carboxylic acid groups on the backbone $[10,22]$ and the $\alpha$-ether-linkages are con-
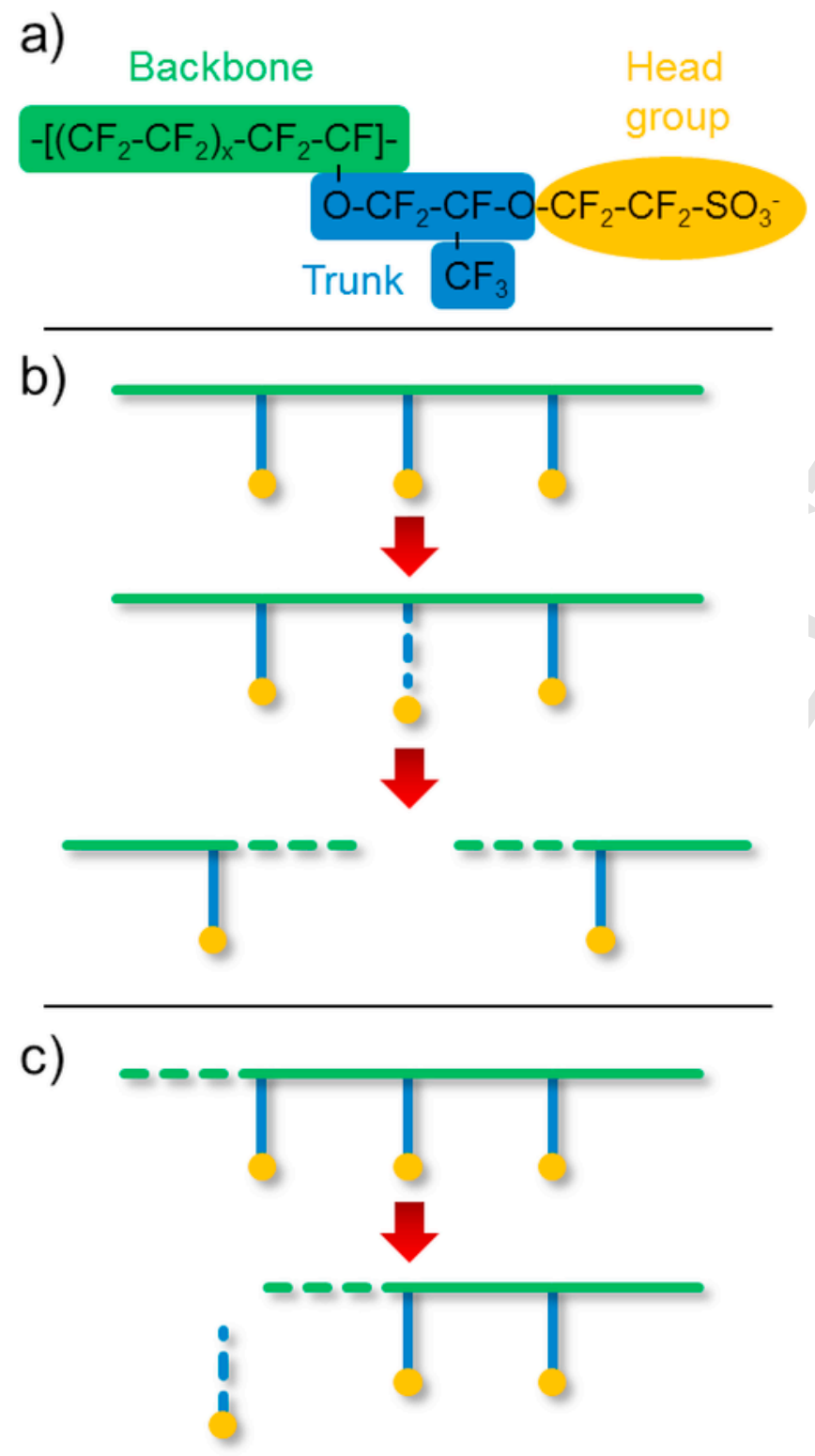

Fig. 4. a) Chemical structure of Nafion ${ }^{\circledR}$ and its coarse-grained simplification according to [8]. b) Side-chain scission and unzipping along the side-chain. c) Unzipping along the backbone. sidered as weak spots [22,24-30]. Consequently, the polymer structure is simplified using the radically coarse-grained approach of [8]. The side-chains are separated at the $\alpha$-ether-linkages into trunk- and head groups. As a third structure, the part of the backbone between two side-chains is considered.

Degradation is assumed to proceed via three mechanisms:

1. Side-chain scission: When the $\alpha$-ether-linkage is attacked, the head group is cut from the side chain and a carboxylic acid group is created on the trunk. Thus, the trunk unit becomes 'activated', i.e. susceptible to chemical degradation via the unzipping mechanism (see Fig. 4 b) middle).

2. Unzipping along the side-chain: The activated trunk units gets destroyed in a sequence of unzipping steps resulting in two carboxylic acid groups on the polymer backbone. Consequently, these parts of the backbone become activated (see Fig. 4 b) bottom). Through this step, degradation accelerates as more carboxylic acid groups are created.

3. Unzipping along the backbone: Once a carboxylic acid group is located on the backbone, it is degraded in a sequence of unzipping steps. When this process reaches the junction with a side-chain, it is lost indirectly (see Fig. 4 c)).

In order to describe the processes discussed above, additional balance equations for the five membrane species backbone (bb), activated backbone (bba), trunk (t), activated trunk (ta) and head group (h) are solved. Since these species are considered immobile, the equations are given by

$\frac{\partial \phi_{i o n} c^{j}}{\partial t}-q^{j}=0$

The degradation reactions are assumed to proceed via a single rate-determining step (RDS). With the simplified physical model, they are expressed as pseudo reactions given in Table 5 .

With the given parameters, the rate constant for the side-chain scission $k^{11}$ at $353.15 \mathrm{~K}$ is $0.24 \mathrm{~m}^{3} \mathrm{~mol}^{-1} \mathrm{~s}^{-1}$, where in Ref. [8], the corresponding value is 44 . This deviation by two orders of magnitude is due to the overestimation of the $\mathrm{HO}^{\bullet}$ concentration in Ref. [8] as discussed in Section 2.4. However, the rate constant used here for reaction 11 at the reference temperature is six orders of magnitude below the value found in Ref. [55]. With the room temperature value of [55], even when assuming an activation energy of zero, the rate constant of the side-chain scission at $353.15 \mathrm{~K}$ would exceed the given value by four orders of magnitude. With such a fast degradation mechanism, the polymer would quickly lose all the sulfonic acid groups and become an non-conducting PTFE membrane. This indicates that degradation in Nafion ${ }^{\circledR}$ via side-chain scission must be much slower than the reaction of model compounds in an aqueous solution used in the experimental study [55].

Unzipping along the activated trunks and backbones is assumed to proceed in $N^{j}$ consecutive steps, where the value of $N^{j}$ depends the backbone length between neighboring side-chains and the side chain length. According to [56], the integrated reaction rate for such a re-

Table 5

Set of degradation reactions considered in the model.

\begin{tabular}{lclll}
\hline Nr. & Reaction & $\begin{array}{l}k_{r e f}^{i} / \mathrm{m}^{3} \\
\mathrm{~mol}^{-1} \mathrm{~s}^{-1}\end{array}$ & $\begin{array}{l}E_{\text {act }}^{i} / \mathrm{J} \\
\mathrm{mol}^{-1}\end{array}$ & Ref. \\
\hline 11 & $\mathrm{HO}+$ head group $\rightarrow$ products & $3 \times 10^{-3}$ & $\begin{array}{l}7 \times 10^{4} \\
\text { a }\end{array}$ & fitted \\
12 & $\mathrm{HO}^{\bullet}+$ activated trunk $\rightarrow$ products & $7.9 \times 10^{2}$ & $7 \times 10^{4}$ & {$[4,55]$} \\
13 & $\mathrm{HO}^{\bullet}+$ activated backbone $\rightarrow$ products & $7.9 \times 10^{2}$ & $7 \times 10^{4}$ & {$[4,55]$} \\
\hline
\end{tabular}

a Assumed to be the same as for unzipping. 
action $i$ can be written as

$r^{i}=\phi_{i o n} \frac{k^{i}}{N^{j}} \prod_{j}\left(c^{j}\right)^{v^{i, j}}$.

Therefore, the rates for the head group-, activated trunk- and activated backbone loss are given by

$r^{11}=\phi_{\text {ion }} k^{11} c^{\mathrm{HO} \bullet} c^{\mathrm{h}}$

$r^{12}=\phi_{i o n} \frac{k^{12}}{N^{\mathrm{t}}} c^{\mathrm{HO}} \cdot c^{\mathrm{ta}}$

and

$r^{13}=\phi_{i o n} \frac{k^{13}}{N^{\mathrm{bb}}} c^{\mathrm{HO} \bullet} c^{\mathrm{bba}}$

respectively. Further, trunks, activated trunks and head groups may be lost indirectly when unzipping along the backbone reaches a junction to a side-chain as depicted in Fig. $4 \mathrm{c}$ ). The corresponding rates for the indirect losses are given by

$r^{\mathrm{t}, \text { in }}=r^{13} \frac{c^{\mathrm{t}}}{c^{\mathrm{t}}+c^{\mathrm{ta}}}$

$r^{\mathrm{ta}, \text { in }}=r^{13} \frac{c^{\mathrm{ta}}}{c^{\mathrm{t}}+c^{\mathrm{ta}}}$

and

$r^{\mathrm{h}, \text { in }}=r^{13} \frac{c^{\mathrm{h}}}{c^{\mathrm{t}}+c^{\mathrm{ta}}}$.

Ghelichi et al. [8] used the terms $c^{\mathrm{t}} / c^{\mathrm{h} \text {,init }}, c^{\mathrm{ta}} / c^{\mathrm{h} \text {,init }}$ and $c^{\mathrm{h}} / c^{\mathrm{h} \text {,init }}$ in Eqs. (29)-(31) respectively, where $c^{\text {h,init }}$ denotes the initial head group concentration. This leads to an underestimation of the indirect losses since it neglects the evolution of the polymer due to degradation. Consequently, the equivalent weight of the polymer may decrease which is not meaningful for the given model of the polymer structure.

To sum up, the source terms of Eq. (24) for the head groups, trunks, activated trunks, backbones, and activated backbones are given by the following equations.

$q^{\mathrm{h}}=-r^{11}-r^{\mathrm{h}, \text { in }}$

$q^{\mathrm{t}}=-r^{11}-r^{\mathrm{t}, \text { in }}$

$q^{\mathrm{ta}}=r^{11}-r^{12}-r^{\mathrm{ta}, \text { in }}$

$q^{\mathrm{bb}}=-2 r^{12}-r^{13}$

$q^{\mathrm{bba}}=2 r^{12}$

In the AST experiments [31], the fluoride emission rate (FER) as a measure for the chemical membrane degradation has been measured using ion chromatography. To compare the model results with the experiments, the FER is calculated using

$$
q^{\mathrm{F}}=\left(r^{11}+r^{h, i n}\right) n^{\mathrm{h}}+\left(r^{12}+r^{\mathrm{t}, \text { in }}+r^{\mathrm{ta}, \mathrm{in}}\right) n^{\mathrm{t}}+r^{13} n^{\mathrm{bb}}
$$

where $n^{\mathrm{h}}, n^{\mathrm{t}}$ and $n^{\mathrm{bb}}$ denote the number of fluorine atoms per head group, trunk and backbone respectively.

Further, in Ref. [31], the change of the membrane thickness due to chemical membrane degradation was determined. Therefore, for the purpose of model validation, the change of the membrane mass per control volume is calculated. Assuming a constant density of the mem- brane, this loss of mass can be related directly to a change in membrane thickness. In this study, the effects of membrane thinning are taken into account without the necessity to use of an adaptive simulation grid. For this purpose, the $\mathrm{x}$ - or through-plane component of the gradients, $\nabla_{x}$, used for the calculation of the local fluxes is scaled with the density ratio:

$\nabla_{x, e f f}=\frac{\rho_{\text {init }}}{\rho(t)} \nabla_{x}$

where $\rho_{\text {init }}$ and $\rho(t)$ denote the initial membrane density and the membrane density at time $t$, respectively.

\subsection{Initial-, boundary and coupling conditions}

The relationships used for the calculation of the initial conditions in the PEM domain are listed in Table 6.

In the electrodes, the initial mole fraction of hydrogen peroxide is set to zero and the concentrations of $\mathrm{Fe}^{2+}$ and $\mathrm{Fe}^{3+}$ is set to $0.022 \mathrm{~mol} \mathrm{~m}^{-3}$ in accordance with the initial conditions in the PEM domain.

The boundary conditions for hydrogen peroxide in the electrodes are set as described in Ref. [1]. For the iron ions, identical to the protons, Neumann no flow conditions are applied on the CL/MPL interfaces. For the polymer and radical species, Neumann no flow conditions are set on the boundary of the PEM domain.

For the coupling of $\mathrm{H}_{2} \mathrm{O}_{2}$ transport in the electrodes and the polymer electrolyte membrane, chemical equilibrium is assumed. In the PEM domain, a Dirichlet type coupling condition is set. The molar concentration of hydrogen peroxide on the coupling interfaces is calculated from the local conditions in the electrodes using Eq. (13). In return, a Neumann type flux coupling condition in the electrode domains is set.

The iron concentration across the CL/PEM interfaces is assumed to be continuous.

Table 6

Initial conditions for the degradation model.

\begin{tabular}{|c|c|c|}
\hline Property/Equation & Units & Ref. \\
\hline \multicolumn{3}{|l|}{ Polymer density: } \\
\hline$\rho_{\text {init }}=2000$ & $\mathrm{~kg} \mathrm{~m}^{-3}$ & [32] \\
\hline \multicolumn{3}{|l|}{ Polymer chain lengths: } \\
\hline$N^{\mathrm{bb}}=14$ & & {$[8]$} \\
\hline$N^{t}=2$ & & {$[8]$} \\
\hline \multicolumn{3}{|l|}{ Molar mass of polymer constituents ${ }^{\mathrm{a}}$ : } \\
\hline$M^{\mathrm{h}}=M^{\mathrm{S}}+3 M^{\mathrm{O}}+2 M^{\mathrm{C}}+4 M^{\mathrm{F}}$ & $\mathrm{kg} \mathrm{mol}^{-1}$ & \\
\hline$M^{\mathrm{bb}}=\left(M^{\mathrm{C}}+2 M^{\mathrm{F}}\right) N^{\mathrm{bb}}+M^{\mathrm{C}}+M^{\mathrm{F}}$ & $\mathrm{kg} \mathrm{mol}^{-1}$ & \\
\hline$M^{\mathrm{t}}=\left(M^{\mathrm{C}}+2 M^{\mathrm{F}}\right) N^{\mathrm{t}}+2 M^{\mathrm{O}}+M^{\mathrm{C}}+2 M^{\mathrm{F}}$ & $\mathrm{kg} \mathrm{mol}^{-1}$ & \\
\hline \multicolumn{3}{|l|}{ Equivalent weight: } \\
\hline$E W_{\text {init }}=M^{\mathrm{h}}+M^{\mathrm{bb}}+M^{\mathrm{t}}$ & $\mathrm{kg} \mathrm{mol}^{-1}$ & \\
\hline \multicolumn{3}{|l|}{ Initial concentrations: } \\
\hline$c_{\text {init }}^{\mathrm{H}_{2} \mathrm{O}_{2}}=0$ & $\mathrm{~mol} \mathrm{~m}^{-3}$ & \\
\hline$c_{\text {init }}^{\mathrm{Fe}^{2+}}=0.022^{\text {b }}$ & $\mathrm{mol} \mathrm{m}^{-3}$ & \\
\hline$c_{\text {init }}^{\mathrm{Fe}^{3+}}=0.022^{\mathrm{b}}$ & $\mathrm{mol} \mathrm{m}^{-3}$ & \\
\hline$c_{\text {init }}^{\mathrm{h}}=\rho_{\text {init }} / E W_{\text {init }}$ & $\mathrm{mol} \mathrm{m}^{-3}$ & \\
\hline$c_{\text {init }}^{\mathrm{bba}}=0.004 c_{\text {init }}^{\mathrm{h}}$ & $\mathrm{mol} \mathrm{m}^{-3}$ & {$[8]$} \\
\hline$c_{\text {init }}^{\mathrm{bb}}=(1-0.004) c_{\text {init }}^{\mathrm{h}}$ & $\mathrm{mol} \mathrm{m}^{-3}$ & \\
\hline$c_{\text {init }}^{\mathrm{t}}=c_{\text {init }}^{\mathrm{h}}$ & $\mathrm{mol} \mathrm{m}^{-3}$ & \\
\hline$c_{\text {init }}^{\mathrm{ta}}=0$ & $\mathrm{~mol} \mathrm{~m}^{-3}$ & \\
\hline$c_{\text {init }}^{\mathrm{HH}}=0$ & $\mathrm{~mol} \mathrm{~m}^{-3}$ & \\
\hline$c_{\text {init }}^{\text {Hit }}=0$ & $\mathrm{~mol} \mathrm{~m}^{-3}$ & \\
\hline$c_{\text {init }}^{\text {int }}=0$ & $\mathrm{~mol} \mathrm{~m}^{-3}$ & \\
\hline
\end{tabular}

a $M^{\mathrm{S}}, M^{\mathrm{O}}, M^{\mathrm{C}}$ and $M^{\mathrm{F}}$ denote the molar mass of sulphur, oxygen, carbon and fluorine respectively.

b Corresponds to $1.26 \mathrm{ppm}$. 


\section{Results}

\subsection{Influence of pressure and relative humidity on chemical degradation}

To validate the chemical membrane degradation model, the simulated FER is compared to experimental values under the three conditions listed in Table 7. The lambda control parameters given in Table 1 , corresponding to OCV operation, were used and cell operation in counter-flow was simulated. To simulate the OCV conditions, galvanostatic simulations were executed with a constant cell current density equal to zero. The simulated temperature was $368.15 \mathrm{~K}$.

Fig. 5 a) shows the comparison between the simulated and measured FER under the three conditions. In Ref. [31], the FER was measured for the anode and cathode exhaust water separately. In the present model, the FER is calculated from integration of Eq. (37) over the PEM domain. Further, transport of degradation products out of the cell is neglected in the model. Therefore, anode and cathode FER cannot be distinguished. Thus, the simulation results are compared to the sum of both experimental values. Additionally, the thinning of the membrane was measured in Ref. [31]. From the comparison of thinning and FER, it was concluded that not all fluorine, released during the ASTs, could be detected because ionomer fragments were not decomposed completely into fluoride ions. Thus, it was estimated that the total amount of fluorine released during the ASTs exceeded the measured value by a factor of 20.8. Since the model does not distinguish between detectable and non-detectable fluorine, the simulation results are compared to the experimental values multiplied with the given factor.

The FER is lowest for low pressure and low relative humidity. Under this condition, the oxygen partial pressure gradient across the PEM is smaller and the permeability of oxygen is reduced [32]. Therefore, the formation of hydrogen peroxide is slow and thus the chemical degradation. Consequently, an increase in pressure accelerates the chemical degradation. The increase of relative humidity has two effects: (i) increase of oxygen permeability with increasing relative humidity and (ii) increased iron ion transport in the CLs and PEM. Since increasing relative humidity increases the ionomer conductivity, gradients of ionic potential are reduced and the drag of iron ions (Eq. (19)) is decreased. Thus, their effective transport across the PEM and CLs accelerates.

In Fig. 5 b), the contributions of the different degradation mechanisms to the overall FER for the AST at low relative humidity and elevated pressure are depicted. With the current parametrization, the unzipping mechanism is fast when compared to the side chain attack (see Table 5). Therefore, unzipping of the backbones is the main contribution to the FER. Further, indirect losses due to unzipping of the backbones are significant. Since activated trunks on the side-chains are degraded quickly, their concentration is extremely low, which makes the indirect loss of these groups insignificant. The FER due to side-chain scission and unzipping of side-chains is three orders of magnitude below the one for unzipping of the backbones.

\subsection{Membrane thinning and OCV evolution}

In Ref. [31], the thinning of the membrane after the tests was investigated. Further, the decrease of the OCV in the course of the ASTs was

Table 7

Operating conditions for the ASTs [31].

\begin{tabular}{llll}
\hline Case & $\mathrm{RH} / \%$ & $p_{\text {anode }} / \mathrm{Pa}$ & $p_{\text {cathode }} / \mathrm{Pa}$ \\
\hline 1 & 30 & $1.5 \times 10^{5}$ & $1.5 \times 10^{5}$ \\
2 & 30 & $2.5 \times 10^{5}$ & $2.3 \times 10^{5}$ \\
3 & 75 & $2.5 \times 10^{5}$ & $2.3 \times 10^{5}$ \\
\hline
\end{tabular}

a)

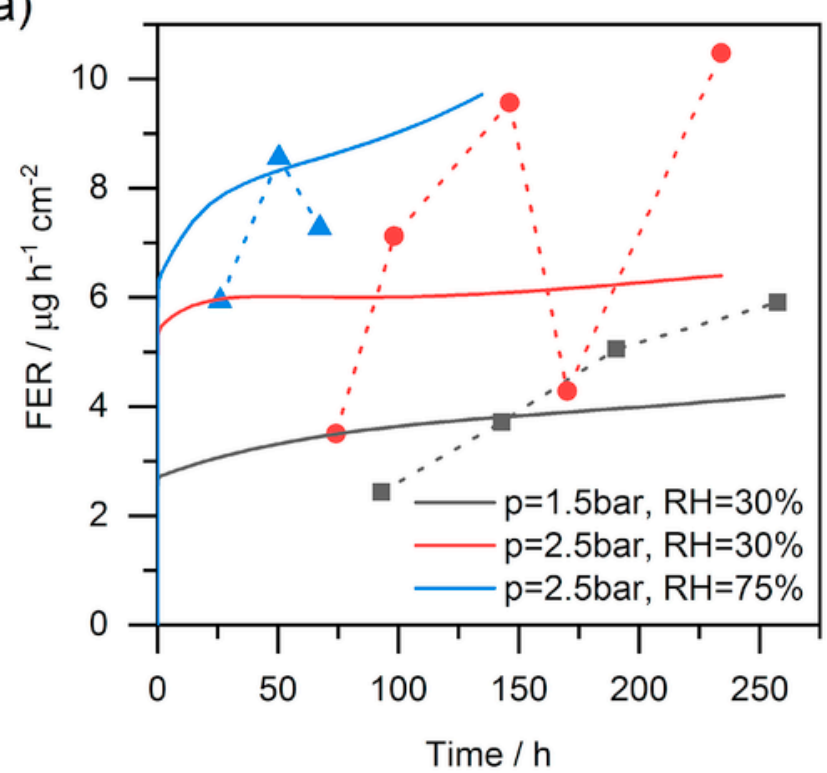

b)

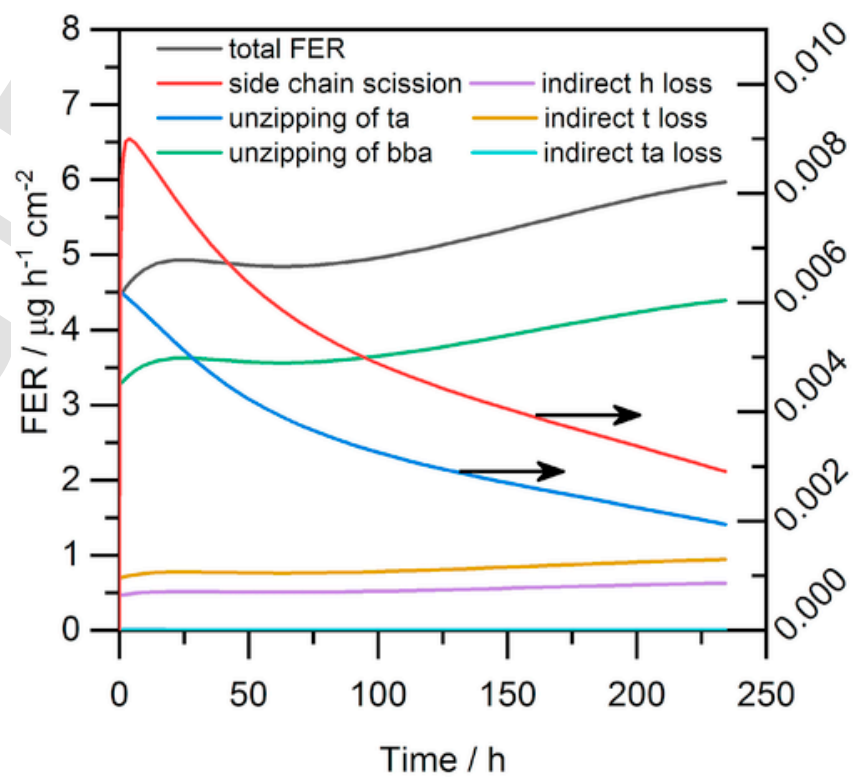

Fig. 5. a) Comparison between experimental and simulated FER during the ASTs. b) Detailed analysis of the simulated FER for case 2 .

measured. Membrane thinning due to chemical degradation will increase the hydrogen cross-over from the anode to the cathode. As hydrogen cross-over causes a small internal short-circuit current which decreases the OCV considerably from its theoretical value [57], thinning of the membrane will lower the OCV. Plots of the simulated membrane thinning and the OCV during the ASTs are depicted in Fig. 6.

Comparison of experimental and simulated values for the membrane thickness at the end of the ASTs shows good agreement for case 2. In case 1, the model overestimates the value given in Ref. [31] to a large extent. No experimental data is available for case 3. One should keep in mind that the experimental values are obtained from the analysis of SEM images. Since membrane thinning will vary across the cell area, many images are required in order to obtain a realistic estimate of the thinning. 
a)

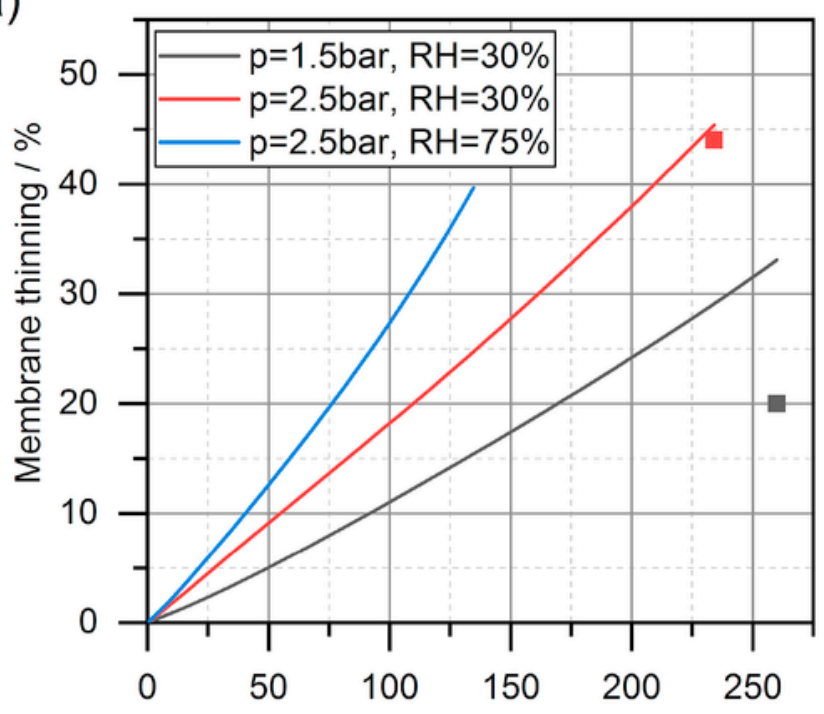

Time / h

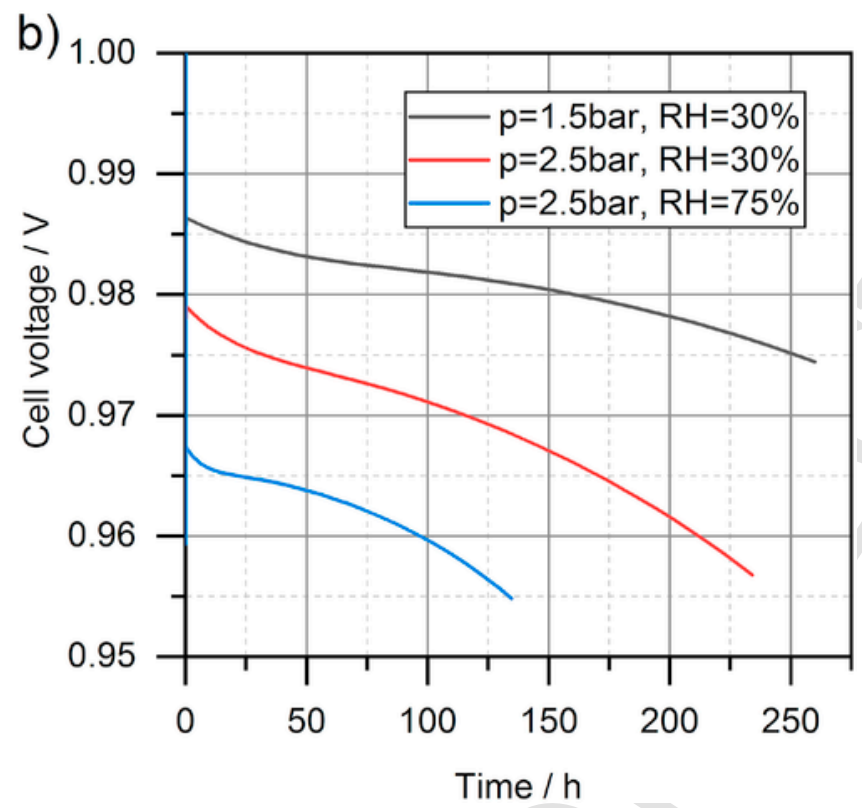

Fig. 6. a) Simulated membrane thinning. Symbols denote experimental observations. b) Simulated decrease of OCV.

The simulated OCV during the ASTs is depicted in Fig. 6 b). In case 1 , the partial pressure gradient of hydrogen across the membrane is lower than in the other two cases. Further, hydrogen permeation is reduced at low relative humidity [32]. Consequently, in this condition, the internal short circuit current is small and the OCV is highest. With increasing pressure and relative humidity, the partial pressure gradient of hydrogen across the membrane and the hydrogen permeability will increase. Therefore, the initial OCV decreases from $\sim 0.985 \mathrm{~V}$ in case 1 to $\sim 0.965 \mathrm{~V}$ in case 3 . As membrane thinning is proportional to the FER, the decrease of OCV during the ASTs increases from case 1 to case 3 .

In Ref. [31] a linear approximation of the OCV reduction is given for the three test cases. Experimental and simulated values are listed in Table 8.

In case 1 and 2 , the model underestimates the experimental value by a factor of five, in case 3 by a factor of 14 . This indicates that addi-
Table 8

Experimental and simulated decrease of $\mathrm{OCV} / \mu \mathrm{V} \mathrm{h}^{-1}$.

\begin{tabular}{lll}
\hline Case & Experiment & Model \\
\hline 1 & 262 & 46 \\
2 & 451 & 95 \\
3 & 492 & 35 \\
\hline
\end{tabular}

tional mechanisms, apart from the increase of gas cross-over due to membrane thinning, must cause the OCV drop during the ASTs.

\subsection{Voltage dependency of chemical degradation}

Experimentally, a strong dependency of chemical membrane degradation on the cell voltage is observed [31]. It is attributed to the potential dependency of $\mathrm{H}_{2} \mathrm{O}_{2}$-formation and the transport of iron ions in the CLs and PEM. In this study, these effects are analyzed in 2D under realistic conditions with a physics-based model. For this purpose, potentiostatic simulations in a voltage range from 0.5 to $0.95 \mathrm{~V}$ were executed. For each condition, the cell voltage was ramped to the desired value and held constant for 1000 s to ensure steady-state. Then, chemical degradation was simulated for $100 \mathrm{~h}$.

Fig. 7 shows the distributions of the $\mathrm{Fe}^{2+}$ concentration and the volumetric FER at the beginning of AST case 3 in the PEM, together with head group concentration after $100 \mathrm{~h}$ of degradation at $0.95,0.85$ and $0.75 \mathrm{~V}$.

At $0.95 \mathrm{~V}$, the concentration of $\mathrm{Fe}^{2+}$ is highest at the anode $\mathrm{CL} / \mathrm{PEM}$ interface close to the anode gas inlet which also corresponds to the cathode gas outlet in counter-flow. The overpotential for the reduction of $\mathrm{Fe}^{3+}$ to $\mathrm{Fe}^{2+}$ Eq. (16) is approximately $-0.53 \mathrm{~V}$ at the anode, while it is $0.03 \mathrm{~V}$ at the cathode. Thus, $\mathrm{Fe}^{2+}$ is produced at the anode, while it is consumed at the cathode. Since the gradient of ionic potential across the PEM is small close to OCV $\left(-8 \mathrm{Vm}^{-1}\right), \mathrm{Fe}^{3+}$ is able to reach the anode side.

In the plot for the volumetric FER, the effect of the PTFE-reinforcement layer is visible. As sources and sinks for all species are multiplied with the ionomer volume fraction $\phi_{\text {ion }}$, the FER is reduced in this part of the membrane. Though the maximum iron ion concentration is close to the anode inlet, the FER increases along the channel since hydrogen peroxide accumulates along the flow direction. The maximum FER is located at anode CL/PEM interface close to the anode outlet in this case.

After $100 \mathrm{~h}$ of chemical degradation, the concentration of sulfonic acid groups, i.e. head groups, in the anode- and cathode side of the PEM are reduced by $17 \%$ and $13 \%$ respectively.

With the cell voltage equal to $0.85 \mathrm{~V}$, the gradients of the $\mathrm{Fe}^{2+}$ concentration across the PEM are not as pronounced as for $0.95 \mathrm{~V}$. The overpotential for iron ion reduction at the anode is still $-0.5 \mathrm{~V}$, however, increasing potential gradients $\left(-234 \mathrm{Vm}^{-1}\right)$ drag the iron ions to the cathode side under this condition.

The maximum for the FER is found close to the cathode CL/PEM interface under this conditions which results from the combined presence of $\mathrm{H}_{2} \mathrm{O}_{2}$ and ferrous ions in this location. Compared to degradation at $0.95 \mathrm{~V}$, the maximum degradation rate is reduced by $54 \%$.

The concentration of sulfonic acid groups in the PEM after degradation exhibits only small gradients in the through-plane direction under this condition. Along the channel, from anode inlet to outlet, the concentration falls from 1810.4 to $1601.9 \mathrm{molm}^{-3}$ which corresponds to a loss of $1 \%$ and $12 \%$ respectively.

At $0.75 \mathrm{~V}$, strong potential gradients $\left(-730 \mathrm{Vm}^{-1}\right)$ drag the iron contaminants to the cathode side. The maximum concentration under this condition is one order of magnitude below the values for the higher cell voltages. 


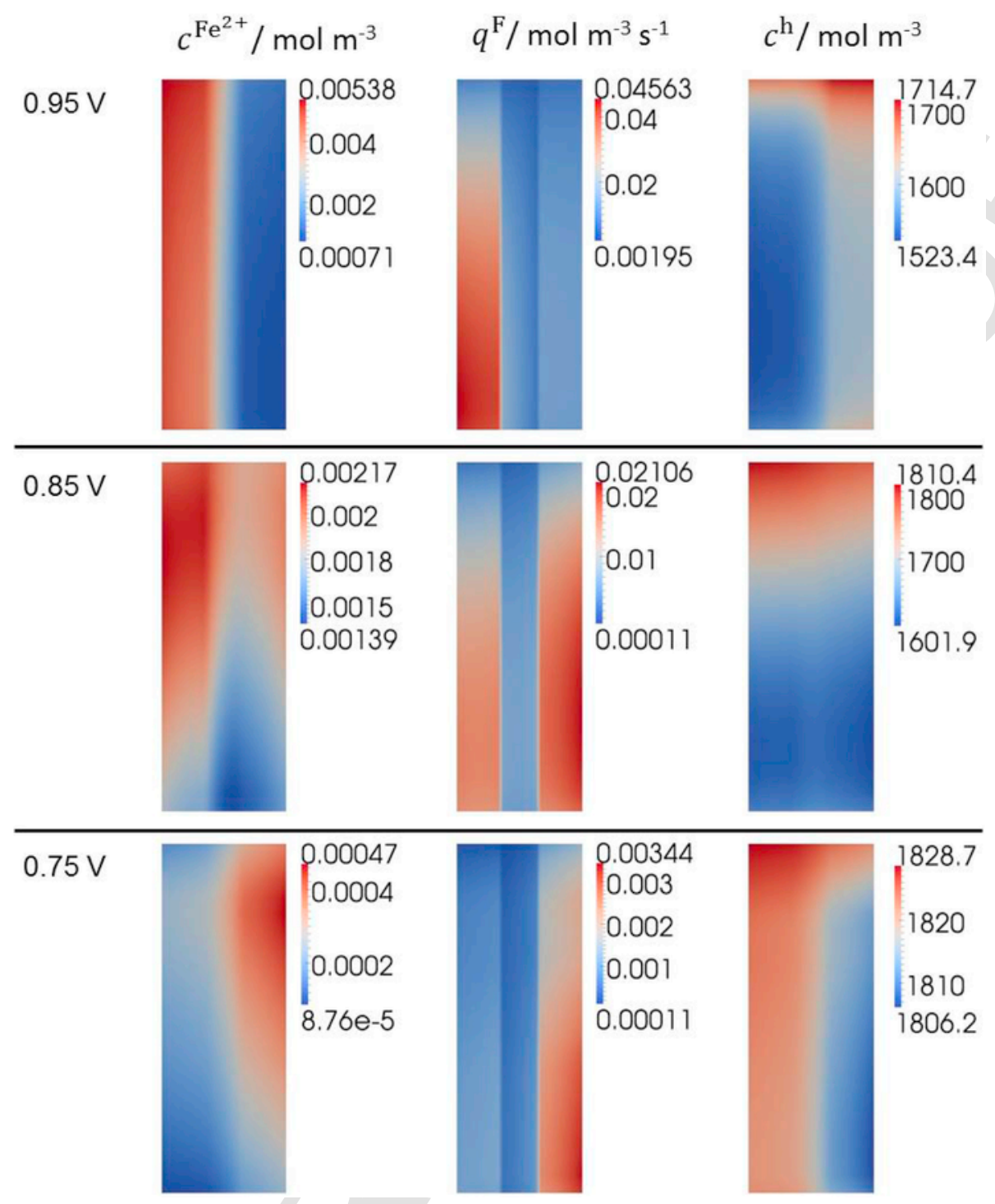

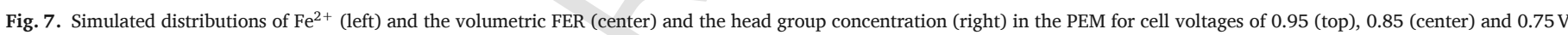
(bottom). The iron ion concentration and FER are displayed for the beginning of the AST (case 3), the head group concentration corresponds to $100 \mathrm{~h}$ of chemical degradation.

In this case, chemical degradation is found to shift to the cathode side close to the CL/PEM interface. After the AST, the minimum concentration of head groups is $1806.2 \mathrm{~mol} \mathrm{~m}^{-3}$, corresponding to a loss of $1 \%$. Therefore, under this condition, chemical degradation becomes insignificant.

In Fig. 8, the initial FER, at the beginning of the ASTs, for different cell voltages in the conditions of the test cases $1-3$ are depicted.

In all test cases, the highest degradation rate is observed at the highest potential close to OCV. As discussed above, this is due to the small gradients of ionic potential in these conditions, which let the iron ions move freely. With decreasing cell voltage, these gradients intensify and the iron ions are dragged to the cathode CL. For cell voltages below $0.7 \mathrm{~V}$, the membrane is swept clean of the majority of the iron contaminants leading to a strong reduction in chemical degradation. Since the ionic conductivity is reduced at low relative humidity, the ionic potential gradients are more pronounced and the voltage dependency is stronger for the dry test cases 1 and 2. Again, degradation increases at higher pressure since the partial pressure gradient of oxygen, leading to hydrogen peroxide formation, becomes larger. Further, degradation increases with increasing humidification since oxygen permeation through the PEM is accelerated in humid conditions.

\section{Conclusions}

In this study, models for gas transport through the PEM, electrochemical hydrogen peroxide formation, transport and an electrochemical reaction of iron ions, radical formation, polymer structure and radical attack on the polymer were combined and implemented into a comprehensive 2D, along-the-channel PEMFC model [1]. The simulated cell performance is in excellent agreement with the experiment. This was achieved by reasonable adjustment of only a few parameters, underlining the predictive capabilities of the performance model. Non-ideal relations for the thermodynamics of hydrogen peroxide in a two-phase-system are considered, motivating a reconsideration of the reaction kinetics hydrogen peroxide formation. An extended set of chemical reactions, leading to hydroxyl radical formation, together with the corresponding temperature dependencies is considered. Where data on the temperature dependency of the reaction kinetics is missing, a sensitivity study was performed in order to highlight the importance of further research in this area. For the kinetics of 


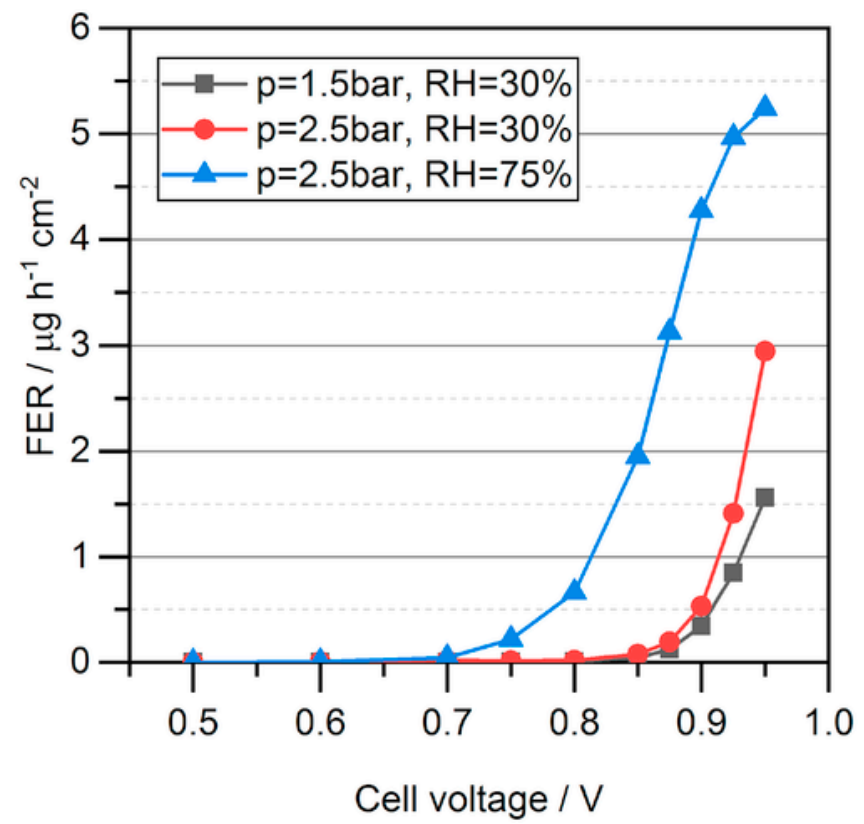

Fig. 8. Simulated dependency of the FER on the cell voltage.

the unzipping- and side-chain-scission-mechanism, literature values were employed where available. A coupling between chemical membrane degradation and fuel cell performance is achieved through simulation of membrane thinning and gas cross-over. The model is validated against experimental data for the FER. Experimental and simulated evolution of OCV during the ASTs are compared. Reasonable agreement between simulated and experimental membrane thinning is achieved. The key findings of this study are:

1. In order to depict chemical membrane degradation in a PEMFC, the high affinity of hydrogen peroxide to the liquid phase needs to be taken into account.

2. Chemical degradation is most pronounced at the anode side of the PEM and highly voltage dependent. To explain these observations, the presence of iron ions, their (electro-)chemical reactions and their transport has to be considered.

3. To simulate in operando chemical degradation, the temperature dependencies of the radical formation reactions need to be taken into account. The influence of the degradation reactions on the steady state concentration of hydroxyl radicals must not be neglected.

4. The rate constants of the degradation reactions in the confined spaces inside the membrane may differ significantly from the values obtained from ex situ measurements of model compounds in aqueous solution.

5. Chemical membrane degradation causes thinning of the membrane which promotes hydrogen cross-over from the anode to the cathode. This causes an increase of the internal short circuit current, a reduction of OCV and therefore cell performance.

6. OCV reduction during the ASTs cannot be explained by increasing hydrogen crossover due to membrane thinning alone. Further investigations on the phenomenon are required.

7. Degradation increases with the operating pressure due to an increase in oxygen cross-over and subsequent hydrogen peroxide formation.

8. Humidification increases chemical membrane degradation since it promotes gas cross-over and reduces potential gradients by improving the ionic conductivity.

9. At OCV, chemical membrane degradation is most pronounced as ionic potential gradients are small and iron ions are able to move freely. With decreasing cell voltage, iron ions get dragged to the cathode side and chemical membrane degradation ceases.

\section{Acknowledgments}

We thank our colleagues at the French Alternative Energies and Atomic Energy Commission (CEA), Grenoble, for the valuable experimental data. Further, we thank the Dumu ${ }^{\mathrm{X}}$ developers at the IWS - Department of Hydromechanics and Modeling of Hydrosystems, University of Stuttgart, for their excellent work and kind support. The research leading to these results has received funding from the European Union's Seventh Framework Program (FP7/2007-2013) for the Fuel Cells and Hydrogen Joint Technology Initiative under grant agreement n 303419.

\begin{tabular}{|c|c|}
\hline Rom & ymbols \\
\hline$a_{\alpha}^{j}$ & activity of species $j$ in phase $\alpha$ \\
\hline$A$ & electrochemically active surface area $/ \mathrm{m}^{2} \mathrm{~m}^{-3}$ \\
\hline$c^{j}$ & concentration of species $\mathrm{j} / \mathrm{mol} \mathrm{m}^{-3}$ \\
\hline$c_{p}$ & isobaric heat capacity $/ \mathrm{J} \mathrm{kg}^{-1} \mathrm{~K}^{-1}$ \\
\hline $\mathbf{d}_{\alpha}^{j}$ & diffusive flux density of species $j$ in phase $\alpha / \mathrm{mol} \mathrm{m}^{-2} \mathrm{~s}^{-1}$ \\
\hline$D$ & diffusion coefficient $/ \mathrm{m}^{2} \mathrm{~s}^{-1}$ \\
\hline$E^{0}$ & equilibrium voltage/V \\
\hline$E_{\text {act }}^{i}$ & activation energy of reaction $i / \mathrm{J} \mathrm{mol}^{-1}$ \\
\hline$E W$ & equivalent weight $/ \mathrm{kg} \mathrm{mol}^{-1}$ \\
\hline & current density $/ \mathrm{A} \mathrm{m}^{2}$ \\
\hline & exchange current density/ $\mathrm{A} \mathrm{m}^{2}$ \\
\hline & rate constant of reaction $i$ /various \\
\hline & relative permeability of phase $\alpha$ \\
\hline & intrinsic permeability $/ \mathrm{m}^{2}$ \\
\hline & number of fluid phases \\
\hline$M^{j}$ & molar mass of species $\mathrm{j} / \mathrm{kg} \mathrm{mol}^{-1}$ \\
\hline$n^{j}$ & number of flourine atoms per species $j$ \\
\hline$N^{j}$ & number of unzipping steps per species $j$ \\
\hline$p^{j}$ & partial pressure of species $\mathrm{j} / \mathrm{Pa}$ \\
\hline$p_{\text {sat }}^{j}$ & vapor pressure of species $j / \mathrm{Pa}$ \\
\hline$p_{\alpha}$ & pressure of phase $\alpha / \mathrm{Pa}$ \\
\hline$P$ & transport parameter/various \\
\hline$q^{j}$ & source/sink term of species $j /$ various \\
\hline$r^{i}$ & volumetric reaction rate of reaction $i / \mathrm{A} \mathrm{m}^{-3}$ \\
\hline$S_{\alpha}$ & saturation of phase $\alpha$ \\
\hline$S_{c h}$ & fraction of expanded water channels in the membrane \\
\hline$t$ & time $/ \mathrm{s}$ \\
\hline$T$ & temperature/K \\
\hline$u^{j}$ & mobility of species $j / \mathrm{s} \mathrm{mol} \mathrm{kg}^{-1}$ \\
\hline $\mathbf{v}_{\alpha}$ & velocity of phase $\alpha / \mathrm{m} \mathrm{s}^{-1}$ \\
\hline & mole fraction of species $j$ in phase $\alpha$ \\
\hline & charge number of species $j$ \\
\hline
\end{tabular}

Greek symbols

$\alpha^{i} \quad$ transfer coefficient of reaction $i$

$\delta_{\text {ion }} \quad$ ionomer film thickness $/ \mathrm{m}$

$\eta \quad$ overpotential/V

$\theta^{j} \quad$ surface coverage of species $j$

$\lambda^{f l u x, j} \quad$ lambda-control parameter of species $j$

$\nabla_{x} \quad$ x-component of gradient $\nabla$

$\mu_{\alpha} \quad$ dynamic viscosity of phase $\alpha$

$\rho \quad$ mass density of the ionomer $/ \mathrm{kg} \mathrm{m}^{-3}$

$\rho_{\text {mol, } \alpha} \quad$ molar density of phase $\alpha / \mathrm{mol} \mathrm{m}^{-3}$

$\nu^{i, j} \quad$ stoichiometry coefficient of species $j$ in reaction $i$

$\phi \quad$ volume fraction or porosity 
$\Phi$

$\chi \quad$ selectivity for $\mathrm{H}_{2} \mathrm{O}_{2}$ formation

$\xi^{j} \quad$ storage term of species $j$ /various

$\psi^{j} \quad$ gas permeation coefficient of species $j / \mathrm{mol} \mathrm{s}^{-1} \mathrm{~m}^{-1} \mathrm{~Pa}^{-1}$

$\Psi^{j} \quad$ flux term of species $j /$ various

\section{References}

[1] G.A. Futter, P. Gazdzicki, K.A. Friedrich, A. Latz, T. Jahnke, Physical modeling of polymer-electrolyte membrane fuel cells: understanding water management and impedance spectra, J. Power Sources 391 (2018) 148-161 https://doi.org/10. 1016/j.jpowsour.2018.04.070 http://www.sciencedirect.com/science/article/pii/ S0378775318304130.

[2] J. Wu, X.Z. Yuan, J.J. Martin, H. Wang, J. Zhang, J. Shen, S. Wu, W. Merida, A review of PEM fuel cell durability: degradation mechanisms and mitigation strategies, J. Power Sources 184 (1) (2008) 104-119, https://doi.org/10.1016/j. jpowsour.2008.06.006 http://linkinghub.elsevier.com/retrieve/pii/ S0378775308011968.

[3] F. Liu, B. Yi, D. Xing, J. Yu, H. Zhang, Nafion/PTFE composite membranes for fuel cell applications, J. Membr. Sci. 212 (1-2) (2003) 213-223, https://doi.org/10. 1016/S0376-7388(02)00503-3.

[4] L. Gubler, S.M. Dockheer, W.H. Koppenol, Radical (HO•, $\mathrm{H}^{\bullet}$ and ) $\mathrm{HOO}^{\bullet}$ formation and ionomer degradation in polymer electrolyte fuel cells, J. Electrochem. Soc. 158 (7) (2011) B755-B769, https://doi.org/10.1149/1.3581040.

[5] C. Chen, T.F. Fuller, XPS analysis of polymer membrane degradation in PEMFCs, J. Electrochem. Soc. 156 (10) (2009) B1218-B1224, https://doi.org/10.1149/1. 3187731 .

[6] M. Gummalla, V.V. Atrazhev, D. Condit, N. Cipollini, T. Madden, N.Y. Kuzminyh, D. Weiss, S.F. Burlatsky, Degradation of polymer-electrolyte membranes in fuel cells II. Theoretical model, J. Electrochem. Soc. 157 (11) (2010) B1542, https:// doi.org/10.1149/1.3481450 http://jes.ecsdl.org/cgi/doi/10.1149/1.3481450.

[7] A.A. Shah, T.R. Ralph, F.C. Walsh, Modeling and simulation of the degradation of perfluorinated ion-exchange membranes in PEM fuel cells, J. Electrochem. Soc. 156 (4) (2009) B465-B484, https://doi.org/10.1149/1.3077573.

[8] M. Ghelichi, P.-É.A. Melchy, M.H. Eikerling, Radically coarse-grained approach to the modeling of chemical degradation in fuel cell ionomers, J. Phys. Chem. B 118 (38) (2014) 11375-11386, https://doi.org/10.1021/jp506333p.

[9] F. Haber, J. Weiss, The catalytic decomposition of hydrogen peroxide by iron salts, Proc. Math. Phys. Eng. Sci. 147 (861) (1934) 332-351, https://doi.org/10.1098/ rspa.1934.0221.

[10] D.E. Curtin, R.D. Lousenberg, T.J. Henry, P.C. Tangeman, M.E. Tisack, Advanced materials for improved PEMFC performance and life, J. Power Sources 131 (1-2) (2004) 41-48, https://doi.org/10.1016/j.jpowsour.2004.01.023.

[11] A. Pozio, R. Silva, M. De Francesco, L. Giorgi, Nafion degradation in PEFCs from end plate iron contamination, Electrochim. Acta 48 (11) (2003) 1543-1549, https: //doi.org/10.1016/S0013-4686(03)00026-4 http://linkinghub.elsevier.com/ retrieve/pii/S0013468603000264.

[12] M.J. Workman, M. Dzara, C. Ngo, S. Pylypenko, A. Serov, S. McKinney, J. Gordon, P. Atanassov, K. Artyushkova, Platinum group metal-free electrocatalysts: effects of synthesis on structure and performance in proton-exchange membrane fuel cell cathodes, J. Power Sources 348 (2017) 30-39, https://doi.org/10.1016/j. jpowsour.2017.02.067 https://doi.org/10.1016/j.jpowsour.2017.02.067.

[13] G. Zhang, R. Chenitz, M. Lefèvre, S. Sun, J.P. Dodelet, Is iron involved in the lack of stability of $\mathrm{Fe} / \mathrm{N} / \mathrm{C}$ electrocatalysts used to reduce oxygen at the cathode of PEM fuel cells?, Nanomater. Energy 29 (2016) 111-125, https://doi.org/10.1016/j. nanoen.2016.02.038 https://doi.org/10.1016/j.nanoen.2016.02.038.

[14] Y. Chen, R. Gokhale, A. Serov, K. Artyushkova, P. Atanassov, Novel highly active and selective Fe-N-C oxygen reduction electrocatalysts derived from in-situ polymerization pyrolysis, Nanomater. Energy 38 (April) (2017) 201-209, https://doi. org/10.1016/j.nanoen.2017.05.059 https://doi.org/10.1016/j.nanoen.2017.05. 059.

[15] S. Stariha, K. Artyushkova, M.J. Workman, A. Serov, S. Mckinney, B. Halevi, P. Atanassov, PGM-free Fe-N-C catalysts for oxygen reduction reaction: catalyst layer design, J. Power Sources 326 (2016) 43-49, https://doi.org/10.1016/j.jpowsour. 2016.06.098 https://doi.org/10.1016/j.jpowsour.2016.06.098.

[16] L. Yang, N. Larouche, R. Chenitz, G. Zhang, M. Lefèvre, J.P. Dodelet, Activity, performance, and durability for the reduction of oxygen in PEM fuel cells, of Fe/N/C electrocatalysts obtained from the pyrolysis of metal-organic-framework and iron porphyrin precursors, Electrochim. Acta 159 (2015) 184-197, https://doi.org/10. 1016/j.electacta.2015.01.201 https://doi.org/10.1016/j.electacta.2015.01.201.

[17] C.H. Choi, C. Baldizzone, J.-P. Grote, A.K. Schuppert, F. Jaouen, K.J. Mayrhofer, Stability of Fe-N-C catalysts in acidic medium studied by operando spectroscopy, Angew. Chem. Int. Ed. 54 (2015) 12753-12757, https://doi.org/10.1002/anie. 201504903

[18] K.H. Wong, E. Kjeang, Macroscopic in-situ modeling of chemical membrane degradation in polymer electrolyte fuel cells, J. Electrochem. Soc. 161 (9) (2014) F823-F832, https://doi.org/10.1149/2.0031409jes.

[19] R. Coulon, Modélisation de la dégradation chimique de membranes dans les piles à combustible à membrane électrolyte polymère, Ph.D. thesis Université de Grenoble, 2012 https://tel.archives-ouvertes.fr/tel-00767412/document.
[20] K.H. Wong, E. Kjeang, Mitigation of chemical membrane degradation in fuel cells: understanding the effect of cell voltage and iron ion redox cycle, ChemSusChem 8 (6) (2015) 1072-1082, https://doi.org/10.1002/cssc.201402957.

[21] T. Jahnke, G. Futter, A. Latz, T. Malkow, G. Papakonstantinou, G. Tsotridis, P. Schott, M. Gérard, M. Quinaud, M. Quiroga, A.A. Franco, K. Malek, F. Calle-Vallejo, R. Ferreira De Morais, T. Kerber, P. Sautet, D. Loffreda, S. Strahl, M. Serra, P. Polverino, C. Pianese, M. Mayur, W.G. Bessler, C. Kompis, Performance and degradation of proton exchange membrane fuel cells: state of the art in modeling from atomistic to system scale, J. Power Sources 304 (2016) 207-233, https:// doi.org/10.1016/j.jpowsour.2015.11.041.

[22] L. Ghassemzadeh, K.-D. Kreuer, J. Maier, K. Mu, Chemical degradation of nafion membranes under mimic fuel cell conditions as investigated by solid-state NMR spectroscopy, J. Phys. Chem. C 114 (35) (2010) 14635-14645.

[23] J. Healy, C. Hayden, T. Xie, K. Olson, R. Waldo, M. Brundage, H. Gasteiger, J. Abbott, Aspects of the chemical degradation of PFSA ionomers used in PEM fuel cells, Fuel Cell. 5 (2) (2005) 302-308, https://doi.org/10.1002/fuce.200400050.

[24] T. Xie, C.A. Hayden, A kinetic model for the chemical degradation of perfluorinated sulfonic acid ionomers: weak end groups versus side chain cleavage, Polymer 48 (19) (2007) 5497-5506, https://doi.org/10.1016/j.polymer.2007.07.043

[25] C. Chen, T.F. Fuller, The effect of humidity on the degradation of Nafion ${ }^{\circledR}$ membrane, Polym. Degrad. Stabil. 94 (9) (2009) 1436-1447, https://doi.org/10.1016/ j.polymdegradstab.2009.05.016.

[26] T. Ishimoto, T. Ogura, M. Koyama, Theoretical study on chemical degradation mechanism of nafion side chain by the attack of $\mathrm{OH}$ radical in polymer electrolyte fuel cell, ECS Transactions 35 (27) (2011) 1-6, https://doi.org/10.1149/1. 3643346.

[27] J.M. Fenton, M.P. Rodgers, D.K. Slattery, X. Huang, V.O. Mittal, L.J. Bonville, H.R. Kunz, Membrane degradation mechanisms and accelerated durability testing of proton exchange membrane fuel cells, ECS Transactions 25 (1) (2009) 233-247, https://doi.org/10.1149/1.3210575.

[28] T. Ishimoto, R. Nagumo, T. Ogura, T. Ishihara, B. Kim, A. Miyamoto, M. Koyama, Chemical degradation mechanism of model compound, $\mathrm{CF}_{3}\left(\mathrm{CF}_{2}\right)_{3} \mathrm{O}\left(\mathrm{CF}_{2}\right)_{2} \mathrm{OCF}_{2} \mathrm{SO}_{3} \mathrm{H}$, of PFSA polymer by attack of hydroxyl radical in PEMFCs, J. Electrochem. Soc. 157 (9) (2010) B1305-B1309, https://doi.org/10. $1149 / 1.3462970$

[29] L. Ghassemzadeh, T.J. Peckham, T. Weissbach, X. Luo, S. Holdcroft, Selective for mation of hydrogen and hydroxyl radicals by electron beam irradiation and their reactivity with perfluorosulfonated acid ionomer, J. Am. Chem. Soc. 135 (42) (2013) 15923-15932, https://doi.org/10.1021/ja408032p.

[30] L. Ghassemzadeh, S. Holdcroft, Quantifying the structural changes of perfluorosulfonated acid ionomer upon reaction with hydroxyl radicals, J. Am. Chem. Soc. 135 (22) (2013) 8181-8184, https://doi.org/10.1021/ja4037466.

[31] M. Chandesris, R. Vincent, L. Guetaz, J.S. Roch, D. Thoby, M. Quinaud, Membrane degradation in PEM fuel cells: from experimental results to semi-empirical degradation laws, Int. J. Hydrogen Energy 42 (12) (2017) 8139-8149, https://doi.org/ 10.1016/j.ijhydene.2017.02.116

[32] A.Z. Weber, J. Newman, Transport in polymer-electrolyte membranes II. Mathematical model, J. Electrochem. Soc. 151 (2) (2004) A311-A325, https://doi.org/ 10.1149/1.1639157.

[33] A.Z. Weber, J. Newman, Transport in polymer-electrolyte membranes I. Physical model, J. Electrochem. Soc. 150 (7) (2003) A1008-A1015, https://doi.org/10. 1149/1.1580822.

[34] P. Bastian, M. Blatt, A. Dedner, C. Engwer, R. Klöfkorn, M. Ohlberger, O. Sander, A generic grid interface for parallel and adaptive scientific computing. Part I: abstract framework, Computing 82 (2-3) (2008) 103-119, https://doi.org/10.1007/ s00607-008-0003-x.

[35] P. Bastian, M. Blatt, A. Dedner, C. Engwer, R. Klöfkorn, R. Kornhuber, M. Ohlberger, O. Sander, A generic grid interface for parallel and adaptive scientific computing. Part II: implementation and tests in DUNE, Computing 82 (2-3) (2008) 121-138, https://doi.org/10.1007/s00607-008-0004-9.

[36] B. Flemisch, M. Darcis, K. Erbertseder, B. Faigle, A. Lauser, K. Mosthaf, P. Nuske, A. Tatomir, M. Wolff, R. Helmig, DuMu ${ }^{X}$ : DUNE for multi- $\{$ phase, component, scale, physics, ... $\}$ flow and transport in porous media, Adv. Water Resour. 34 (9) (2011) 1102-1112, https://doi.org/10.1016/j.advwatres.2011.03.007

[37] T.E. Springer, T.A. Zawodzinski, S. Gottesfeld, Polymer electrolyte fuel cell model, J. Electrochem. Soc. 138 (8) (1991) 2334-2342, https://doi.org/10.1149/1. 2085971.

[38] V.A. Sethuraman, J.W. Weidner, A.T. Haug, S. Motupally, L.V. Protsailo, Hydrogen peroxide formation rates in a PEMFC anode and cathode, J. Electrochem. Soc. 155 (1) (2008) https://doi.org/10.1149/1.2801980, B50-B57.

[39] R. Sander, Compilation of Henrys Law Constants for Inorganic and Organic Species of Potential Importance in Environmental Chemistry, Tech. Rep, Max-Planck Institute of Chemistry, 1999 http://www.henrys-law.org/henry-3.0.pdf.

[40] S.L. Manatt, M.R.R. Manatt, On the analyses of mixture vapor pressure data: the hydrogen peroxide/water system and its excess thermodynamic functions, Chemistry 10 (24) (2004) 6540-6557, https://doi.org/10.1002/chem.200400104.

[41] C. Chen, T.F. Fuller, Modeling of $\mathrm{H} 2 \mathrm{O} 2$ formation in PEMFCs, Electrochim. Acta 54 (16) (2009) 3984-3995, https://doi.org/10.1016/j.electacta.2009.02.021 http:// linkinghub.elsevier.com/retrieve/pii/S0013468609002412.

[42] M.C. Pelsozy, Investigation of Hydrogen Peroxide Production and Transport in a Proton Exchange Membrane Fuel Cell and the Atom Resolved Micro-characterization of its Catalyst, Ph.D. thesis Case Western Reserve University, 2008 http:// rave.ohiolink.edu/etdc/view?acc_num $=$ case1209692060. 
[43] D.O. Whittemore, D. Langmuir, Standard Electrode Potential of $\mathrm{Fe}^{3+}+=\mathrm{e}^{-} \cdot \mathrm{frFe}^{2+}$ om 5-35C, J. Chem. Eng. Data 17 (3) (1972) 288-290, https://doi.org/10.1021/ je60054a002.

[44] T. Rigg, W. Taylor, J. Weiss, The rate constant of the bimolecular reaction between hydrogen peroxide and ferrous ion, J. Chem. Phys. 22 (4) (1954) 575-577, https:// doi.org/10.1063/1.1740127.

[45] G.G. Jayson, B.J. Parsons, A.J. Swallow, Oxidation of ferrous ions by perhydroxyl radicals, J. Chem. Soc., Faraday Trans. 1 (3) (1973) 236-242, https://doi.org/10. 1039/f19736900236, 69.

[46] J.D. Rush, B.H.J. Bielski, Pulse radiolysis studies of alkaline iron(III) and iron(VI) solutions. Observation of transient iron complexes with intermediate oxidation states, J. Phys. Chem. 89 (23) (1985) 5062-5066, https://doi.org/10.1021/ ja00263a037.

[47] C. Lee, J. Yoon, Temperature dependence of hydroxyl radical formation in the hv/ $\mathrm{Fe}^{3+} / \mathrm{H}_{2} \mathrm{O}_{2}$ and $\mathrm{Fe}^{3+} / \mathrm{H}_{2} \mathrm{O}_{2}$ systems, Chemosphere 56 (10) (2004) 923-934, https:// doi.org/10.1016/j.chemosphere.2004.04.047.

[48] T. Lundström, H. Christensen, K. Sehested, Reactions of the $\mathrm{HO}_{2}$ radical with $\mathrm{OH}$, $\mathrm{H}, \mathrm{a} \mathrm{Fe}{ }^{2+}$ nd at $\mathrm{Cu}^{2+}$ elevated temperatures, Radiat. Phys. Chem. 69 (3) (2004) 211-216, https://doi.org/10.1016/S0969-806X(03)00462-6.

[49] G.V. Buxton, C.L. Greenstock, W.P. Helman, A.B. Ross, Critical Review of rate constants for reactions of hydrated electrons, hydrogen atoms and hydroxyl radicals (.OH/O') in Aqueous Solution, J. Phys. Chem. Ref. Data 17 (2) (1988) 513-886, https://doi.org/10.1063/1.555805.

[50] H. Christensen, K. Sehested, H. Corfitzen, Reactions of hydroxyl radicals with hydrogen peroxide at ambient and elevated temperatures, J. Phys. Chem. 86 (9) (1982) 1588-1590, https://doi.org/10.1021/j100206a023.
[51] W.H. Koppenol, J. Butler, J. W. v. Leeuwen, The haber-weiss cycle, Photochem. Photobiol. 28 (4-5) (1978) 655-658, https://doi.org/10.1111/j.1751-1097.1978. tb06989.x.

[52] F.S. Dainton, J. Rowbottom, The primary radical yield in water. A comparison of the photolysis and radiolysis of solutions of hydrogen peroxide, Trans. Faraday Soc. 49 (1160) (1953) 1160-1173, https://doi.org/10.1039/TF9534901160.

[53] B.H.J. Bielski, Reevaluation of the spectral and kinetic properties of ho2 and o2free radicals, Photochem. Photobiol. 28 (4-5) (1978) 645-649, https://doi.org/10. 1111/j.1751-1097.1978.tb06986.x.

[54] T. Lundström, H. Christensen, K. Sehested, The reaction of hydrogen atoms with hydrogen peroxide as a function of temperature, Radiat. Phys. Chem. 61 (2) (2001) 109-113, https://doi.org/10.1016/S0969-806X(01)00189-X.

[55] A.M. Dreizler, E. Roduner, Reaction kinetics of hydroxyl radicals with model compounds of fuel cell polymer membranes, Fuel Cell. 12 (1) (2012) 132-140, https:// doi.org/10.1002/fuce.201100157.

[56] D.A. Deranleau, General solution of the pseudo first-order rate equations for consecutive reactions with identical rate constants, Experientia 38 (6) (1982) 661-662, https://doi.org/10.1007/BF01964078.

[57] S.A. Vilekar, R. Datta, The effect of hydrogen crossover on open-circuit voltage in polymer electrolyte membrane fuel cells, J. Power Sources 195 (8) (2010) 2241-2247, https://doi.org/10.1016/j.jpowsour.2009.10.023. 